\title{
The Evolution Characteristics of Different Deformation Modes of Shear Slip Surface Based on Acoustic Emission Measurements
}

\section{Qiang Xie}

Chongqing University

zhihui wu ( $\nabla$ Wuzhihui199245@hotmail.com )

Chongqing University https://orcid.org/0000-0002-1385-895X

\section{Yuxin Ban}

Chongqing University

\section{Xiang Fu}

Chongqing Jiaotong University

\section{Zhilin Cao}

Chongqing University

\section{Weichen Sun}

Chongqing University

\section{Bolin Chen}

Chongqing University

\section{Research Article}

Keywords: shear surface deformation, different deformation modes, acoustic emission data, multiple features, identification reference, early warning

Posted Date: June 4th, 2021

DOl: https://doi.org/10.21203/rs.3.rs-557596/v1

License: (c) (1) This work is licensed under a Creative Commons Attribution 4.0 International License. Read Full License 


\title{
The Evolution Characteristics of Different Deformation Modes of
} Shear Slip Surface Based on Acoustic Emission Measurements

\author{
Qiang Xie ${ }^{1}$, Zhihui $\mathrm{Wu}^{1}$, Yuxin Ban ${ }^{1}$, Xiang Fu², Zhilin Cao ${ }^{1}$, Weichen Sun ${ }^{1}$, Bolin $\mathrm{Chen}^{1,3,4}$
}

1. School of Civil Engineering, Chongqing University, No. 174 Shazheng Road, Chongqing 400030, China

2. College of River and Ocean Engineering, Chongqing Jiaotong University, No. 66 Xuefu Road, Chongqing 400074, China

3. Technology Innovation Center of geohazards automatic monitoring, Ministry of Natural Resources, Chongqing Institute of Geology and Mineral Resources, No. 111 Lanxin Road, Chongqing, 401120, China

4. Chongqing Engineering Research Center of Automatic Monitoring for Geological Hazards, Chongqing Institute of Geology and Mineral Resources, No. 111 Lanxin Road, Chongqing, 401120, China

Corresponding author E-mail address: Wuzhihui199245@hotmail.com (Zhihui Wu)

ORCID iD: https://orcid.org/0000-0002-1385-895X

Abstract: To investigate the acoustic emission (AE) precursor detection of landslide failures, a model test aiming at reproducing the typical shear surface deformation of different landslide modes was designed. The evolution characteristics of the $\mathrm{AE}$ signals were analyzed in terms of $\mathrm{AE}$ count, cumulative $\mathrm{AE}$ count, $\mathrm{AE}$ correlation diagrams, and corresponding time-frequency properties. The test results show that for the progressive deformation mode, the AE count experiences a low-level period, an active period and a rapid increase period, and the distribution of correlation diagram hits concentrates in a relatively small scale and then gradually scatters. There is low frequency signals firstly and then high frequency signals, and the energy proportion of the high-frequency signals shows an increasing tendency. For the sudden deformation mode, the magnitude of AE count increases sharply, leading to the cumulative AE count curve rises steeply, and correlation diagram hits distribution turns into relatively scattering rapidly. Furthermore, the high frequency signals and high energy proportion appear much earlier than that of the progressive deformation mode. For steady deformation mode, however, the acoustic emission activity is quite active in the initial stage, the cumulative AE count curve rises sharply and then maintains relatively flat trend, and correlation diagram hits distribution scatters firstly, then the signal hits distribution begins to concentrate in a relatively small scale. There are intensive high-frequency hits and high energy proportion earlier, and later they tend to decay in response to smaller magnitudes of movement. Comprehensive use of multiple features can help identify landslide deformation patterns more accurately under complex natural conditions, which may provide a promising reference for the field warning monitoring of the diverse landslide failures.

Keywords: shear surface deformation; different deformation modes; acoustic emission data; multiple features; identification reference; early warning

\section{Introduction}

Landslide is considered one of the main geological hazards in the world, which has caused enormous loss to the life and property (Wang et al. 2009; Conte et al. 2017; Fan et al. 2018; Michlmayr et al. 2012; Huang 2009; Giri et al., 2018; Huang and Fan 2013). Due to different geological conditions and external environment factors, such as rainfall, earthquake and fluctuation of reservoir level, there are a large number of different geologic hazards more vulnerable to appearing (Hu et al., 2017; Chowdhuri et al., 2018; Tiwari Chen et al., 2018; Li et al., 
2019; Vadivel et al., 2019; Huang et al., 2020; Yin et al. 2015, 2016), especially the slope damage has a huge threat on mountainous town buildings, factory infrastructures and transportation network in mountainous areas worldwide, as shown in Fig. 1. At present, there are greater magnitude of potential landslides in many regions of the world, i.e. more than 5000 landslides or potential landslides have been identified in the Three Gorges Reservoir(TGR) region, which causes the enormous geological hazards threat (Huang et al, 2020; Li and Xu, et al, 2018). Therefore, it is urgent to improve the identification and warning accuracy of the various landslides, which is closely relevant to the prevention and control of geological landslide hazards.

Based on the real-time monitoring methods, identifying different landslide types effectively and providing early prediction information are both very important, and the identification of different landslide behaviour in complex geological conditions is crucial in landslide hazard evaluation (Conte et al. 2012; Chae et al. 2017; Pecoraro et al. 2019; Ju et al. 2020). There is a clear need to understand the deformation characteristics and kinematic evolution process of different landslide modes, thus the landslides failures can be forecasted in a timely and relatively accurate manner, further the prevention measures will be taken timely to enable the evacuation of vulnerable people and maintenance of critical infrastructure, and the losses caused by such natural disasters would be minimized (Milaghardan et al. 2014; Dikshit et al. 2018; Wang et al. 2020).



Fig. 1 Part of regional landslide hazards in the world

The various landslide patterns have different deformation modes and failure behaviors under different stress conditions. Therefore, monitoring the physico-mechanical parameters and their related characteristics during the slope deformation process is very important to judge the damage degree and the disaster mechanism of the landslide. Acoustic emission (AE) has recently been recognized as the feasible technique to monitor landslides movement, which could contain the rich information of the entire landslide evolution process. For decades, researchers have used the measurement and quantification of acoustic emission generated by the sliding deformation of soil slopes to continuously develop monitoring technology strategies (Koerner et al. 1981; Chichibu et al. 1989; Dixon et al. 2003; Shiotani 2006, Smith et al. 2014). These methods usually use waveguides to provide a low attenuation propagation path of acoustic emission signals. Later, researchers developed active waveguide devices (Dixon et al. 2007; Smith et al. 2015), and abundant acoustic emission signals are generated by the backfill material. When the slope is sliding, the soil acts on the backfill material, causing particle-particle interactions, resulting in acoustic emission. Active waveguide acoustic emission monitoring has many advantages over traditional deformation monitoring technology, such as the significant detection of acoustic emission signals, 
effective quantization of reference indexes. Subsequently, many acoustic emission and landslide tests have shown that the slope displacement rate is directly related to the acoustic emission rate generated by the active waveguide. As the deformation rate increases, the acoustic emission rate generated is proportional to the applied displacement rate, (Dixon et al. 2015; Smith et al. 2017; Berg et al. 2018; Deng et al. 2019).

Since scholar Saito made landslide prediction based on the creep test results, researcher have been studying and exploring the slope failure behaviors and the landslide prediction methods (Saito et al. 1961; Saito 1965; Fan et al. 2018; Xu 2011; Hungr et al. 2014). With the increasing number of landslide monitoring cases, the movement patterns of different landslides have been widely recorded and investigated by the researcher and geologists all the world, the monitoring data shows that there are many types of landslide in nature, mainly including progressive landslide mode, sudden landslide mode and steady landslide mode (Xu et al., 2011; Petley and Allison, 1997; Crosta and Agliardi, 2003; Gance et al., 2014; Xu et al., 2020). Many landslide movements present different deformation and failure behaviors under different deformation stages or stress conditions. For the different landslide failure, in the deformation process of shear sliding surface, the waveguide devices material column is subjected to different confining pressures, and the interaction between the particles and the scale of contact stress in the shear zone are significant variation, resulting in difference AE signals emitted. Specifically, the evolution characteristics of $\mathrm{AE}$ parameters are critical for the identification and warning of the different landslides instability.

To date, numerous researchers have been investigating on early warning of slope failures. Although numerous types of sensor-based monitoring techniques, evaluation criterions, warning patterns are available, and they are currently widely used for monitoring of landslide geological hazard, the effective identification reference and warning determination of the different landslide modes are always a difficult problem in view of the extremely complex geological and meteorological conditions, which is not conductive to the prevention and control of landslide hazards. So it becomes important to explore effective identification indicators of deformation stages of different landslide failures, further to provide a timely alert to people in the immediate vicinity of the landslide.

In this study, we conducted the physical model experiment to simulate the different landslides modes by controlling deformation rates. The $\mathrm{AE}$ characteristic parameters, such as the $\mathrm{AE}$ count, amplitude, duration, energy, dominant frequency, and energy proportion, are analyzed and compared during the process of different deformation modes. Furthermore, the tests indicate that the $\mathrm{AE}$ characteristic parameters demonstrate the significant evolution characteristic with the shear surface deformation, and the comprehensive multi-feature analyzing approach may provide effective solutions for detecting physical activities related to specific deformation stages of different landslide failures, also give early warning information to such failures, which can be used to provide a certain reference for further AE detection-based soil landslide warning models.

\section{Mechanical mechanism of different landslide modes}

Landslide is a complex geological hazard, which is greatly affected and restricted by many factors such as geological conditions, hydrological conditions, geotechnical properties, heavy rainfall, etc. Different landslide types have different deformation modes and failure behaviors under various stress conditions. Analyzing the deformation-time curves characteristics of different landslide types, it is found that they are very similar to the rheological test results of rock and soil, with good correspondence and comparability (Zhou et al.1995; Xu et al. 2012). The deformation process of the slope is essentially the creep process of the rock and soil under the external force action. The deformation and failure behavior of slope under different stress conditions can be studied 
according to the creep test results of rock and soil, that is, the possible landslide types and behavior characteristics under different stress conditions. Considering the long-term strength and creep characteristics of rheological mechanics, the possible mechanical state of the landslide during different evolution stages is analyzed.

During the landslide deformation process, the unbalanced sliding force is the essential cause of the landslide evolution. The unbalanced sliding force refers to the difference value between the sliding force $F_{p}$ and the resistance against sliding $F_{R}$, which is recorded as $\Delta F=F_{p}-F_{R}$. The shear stress distributed along the sliding surface induced by $\Delta F$ is called unbalanced shear stress $\Delta \tau$. The dynamic evolution trends of landslides diversification modes is mainly caused by different evolution values of unbalanced shear stress $\Delta \tau$. During the landslide movement process, the mechanical strength of sliding band zone may vary influenced by many factors such as water content. In addition, external factors such as vibration load, slope toe excavation and long-term heavy rainfall, these external factors can further affect sliding force $F_{p}$, further affect sliding shear stress, thus induce different landslides types.
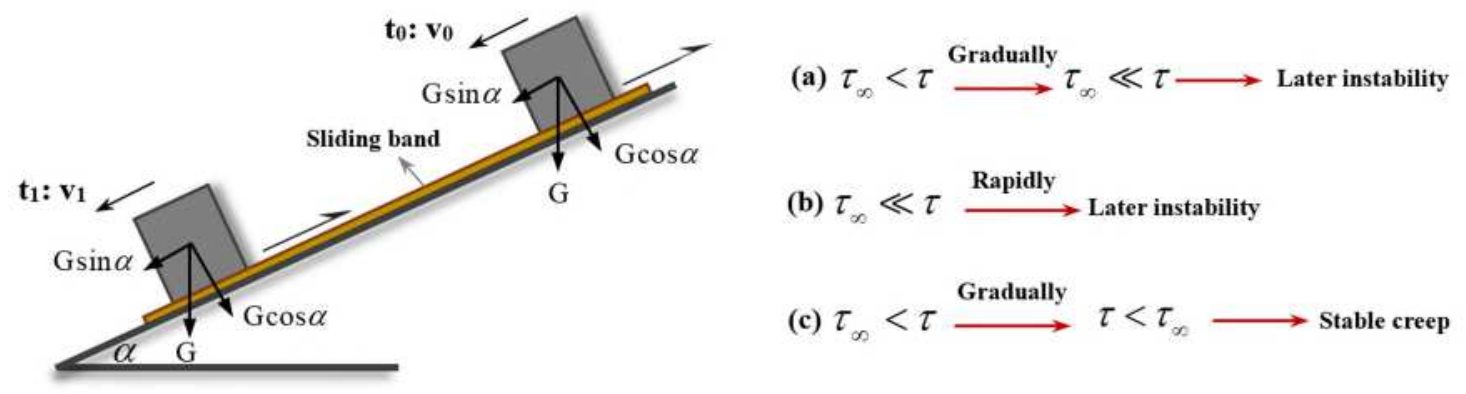

Fig. 2 Simplified landslide mechanics modes(a) progressive deformation mode;(b) sudden deformation mode;(c) steady deformation mode

Mainly, the evolution trend of geotechnical materials creep deformation is determined by the relationship between the shear stress $\tau$ and long-term strength $\tau_{\infty}$ of the sliding band soil.

When the shear stress is slightly greater than long-term strength $\tau_{\infty}<\tau$, the slope will undergo continuous gentle deformation and may undergo a deformation stage with low creep rate. As the deformation continues to evolve, coupled with the influence of external factors such as rainfall, the sliding resistance force provided by the sliding zone continues to decrease. Gradually, the sliding force is far greater than the anti-sliding force provided by the sliding zone soil. Later, as the deformation process continuously evolves, it will enter the accelerating deformation stage eventually, causing the slope body instability and damage, which shows the progressive landslide mode throughout all the process.

If the slope is subjected to strong external factors abruptly, such as earthquake or heavy rainfall, the sliding force may suddenly increase, also the anti-sliding force provided by the sliding band soil loses rapidly, probably the sliding force is much greater than the anti-sliding force in a short time, i.e. $\tau \gg \tau_{\infty}$, thus the landslide deformation rapidly increases and eventually evolves into an accelerating deformation stage. Landslide occurs short-term movement with very high deformation rate, causing the slope body instability and damage in a quite short time. The time from the deformation occurrence to the final slope instability is relatively short, and the rapidly accelerating deformation stage appears without experiencing longer process of low deformation rate, and sudden landslides case is prone to occur.

In earlier stage, if the slope is subjected to strong external factors, the sliding force may suddenly increase, 
larger deformation probably occurs early. However, with the gradual deformation evolution and the external effects attenuation or disappearance, the sliding force will decrease, when the sliding stress does not exceed the long-term strength of the slide zone soil $\tau<\tau_{\infty}$, the landslide deformation mainly appears stable creep under this stress condition, which will undergo long term tiny creep movement, it might maintain a stable state at last, so the steady landslide case may appear.

\section{Experimental system and test procedure}

\subsection{Experimental apparatus}

The shear apparatus was designed to simulate the shear surface deformation of the soil slope sliding, which comprised two steel boxes, each box with the dimensions $0.2 \times 0.2 \times 0.3 \mathrm{~m}$. And the bottom box was fixed on the heavy steel pedestal to prevent movement. For each test, the lubricant was applied on the two boxes interface to reduce the friction force. The apparatus was filled with soil to represent the element of the soil slope. Besides, the steel waveguide could be installed through the soil column with the granule backfills.

In the test, the servo loading system is CMT-5205, the electro-hydraulic servo test machine, equipped with precision oil pump and electro-hydraulic servo valve to perform automatic control, allowing the more experimental displacement variables could be controlled. The maximum test load is $300 \mathrm{kN}$, and the displacement rate is adjustable within the range of $0.001 \sim 500 \mathrm{~mm} / \mathrm{min}$, which fully meets the experimental requirements. The set program is used to maintain a specified displacement rate, then the upward loading device pulls the wire rope, and the wire rope is horizontally connected to the top box to induce the shearing formation in the soil column, so as to control the displacement behaviors of the shear sliding surface, as shown in Fig. 3.



\subsection{Soil and backfills material}

Fig. 3 Experimental apparatus

The $80 \mathrm{~mm}$ diameters hole was reserved by the PVC tube matched the size. An active waveguide, a $30 \mathrm{~mm}$ dia., $1.0 \mathrm{~m}$ long steel tube with $5 \mathrm{~mm}$ wall thickness was installed in the hole with the columnar backfills. Then the soil element model was prepared using the layered filling method. The filling height of each layer was $15 \mathrm{~cm}$, and the soil was uniformly compacted with a constant external force. and the specific particle parameters are showed in the Table 1. 


\begin{tabular}{cccccccc}
\hline $\begin{array}{c}\text { Water content } \\
(\%)\end{array}$ & $\begin{array}{c}\text { Elasticity modulus } \\
(\mathrm{Gpa})\end{array}$ & $\begin{array}{c}\text { Density } \\
\left(\mathrm{kg} / \mathrm{m}^{3}\right)\end{array}$ & $\begin{array}{c}\text { Cohesion } \\
(\mathrm{kPa})\end{array}$ & $\begin{array}{c}\text { Friction } \\
\text { Angle }\left({ }^{\circ}\right)\end{array}$ & $\begin{array}{c}\text { Plastic } \\
\text { limit }(\%)\end{array}$ & $\begin{array}{c}\text { Liquid } \\
\text { limit }(\%)\end{array}$ & Plastic index \\
\hline 17.8 & 0.12 & 1800 & 21.0 & 24.0 & 17 & 40.2 & 23.2 \\
\hline
\end{tabular}

172

Besides, among the series tests on the waveguide with different backfills (glass sand, marble gravel, river sand), the glass sand backfills case shows remarkable variation characteristics for the cumulative AE count, which is closely related to the sliding deformation process. Besides, there is prior AE detection sensitively when using the glass sand backfills compared to the other cases during the initial stage with extremely slow magnitude deformation rate. Moreover, the most evident quantitative correlational relationship between the cumulative AE count and the shear deformation, and the priority $\mathrm{AE}$ detection, it is the potential application for detecting pre-failure processes on soil slope, and providing timely information on the movement status of the various soil slope. Subsequently, a series of displacement-controlled shear tests were conducted on active waveguide models with glass sand granular backfills, to study the AE detection characteristics under different shear deformation movements, and the specific particle parameters are showed in the Table 2.

Table 2 The mechanical parameters properties of backfill materials

\begin{tabular}{ccccc}
\hline Backfills & $\begin{array}{c}\text { Size range } \\
(\mathrm{mm})\end{array}$ & $\begin{array}{c}\text { Particle density: } \\
\left(\mathrm{kg} / \mathrm{m}^{3}\right)\end{array}$ & $\begin{array}{c}\text { Dry density } \\
(\mathrm{kPa})\end{array}$ & $\begin{array}{c}\text { Void } \\
\text { ratio }\end{array}$ \\
\hline glass sand & $2 \sim 5$ & 2936 & 1600 & 0.72 \\
\hline
\end{tabular}

\subsection{AE measurement system}

The DS2AE equipment was adopted, which can collect and display AE signal waveforms and parameters in real time. The acoustic emission sensor is a Nano-30 resonant high-sensitivity sensor with a frequency range of $125 \sim 750 \mathrm{kHz}$. The acoustic emission sampling threshold value was $50 \mathrm{~dB}$ to effectively reduce the noise impact. The waveform sampling rate was 1MSPS. The sensor was fixed by white tape, and the coupling agent was applied between the sensor and the waveguide to reduce the signal attenuation. During the loading process, the displacement-time information and acoustic emission waveforms were collected synchronously.

\subsection{Test procedure}

The displacement-time functions (Table 3 5) were designed to reproduce the evolution process of different landslide modes, all tests were controlled by displacement rate. Through the control system of test machine, input the displacement rate parameters at different moments, and the wire rope linked to the shear box will respond in time, which can accurately control the deformation rate of the shear surface according to the given parameters formulas. The displacement-time curve of the shear sliding surface was automatically controlled, as shown in the Fig. 4 . Thus, the testing process was stable and a smooth displacement-time curve could be obtained. After the tertiary stage of operation, the testing program automatically terminated, and the shear deformation process was completed.

Table 3 Displacement controlled program of the progressive deformation mode

\begin{tabular}{ccccc}
\hline Procedure & $\begin{array}{c}\text { Velocity } \\
(\mathrm{mm} / \mathrm{s})\end{array}$ & $\begin{array}{c}\text { Duration } \\
(\mathrm{s})\end{array}$ & $\begin{array}{c}\text { Cumulative } \\
\text { time}(\mathrm{s})\end{array}$ & $\begin{array}{c}\text { Displacement } \\
(\mathrm{mm})\end{array}$ \\
\hline JZ-1 & 0.01 & 300 & 300 & 3 \\
JZ-2 & 0.02 & 150 & 450 & 6 \\
JZ-3 & 0.0416 & 60 & 510 & 8.5 \\
JZ-4 & 0.08 & 50 & 560 & 12.5
\end{tabular}




$\begin{array}{lcccc}\text { JZ-5 } & 0.0166 & 30 & 590 & 17.5 \\ \text { JZ-6 } & 0.32 & 25 & 615 & 25.5 \\ \text { JZ-7 } & 0.6 & 30 & 645 & 43.5 \\ \text { JZ-8 } & 0.9 & 30 & 675 & 70.5\end{array}$

202

204

Table 4 Displacement controlled program of the sudden deformation mode

\begin{tabular}{ccccc}
\hline Procedure & $\begin{array}{c}\text { Velocity } \\
(\mathrm{mm} / \mathrm{s})\end{array}$ & $\begin{array}{c}\text { Duration } \\
(\mathrm{s})\end{array}$ & $\begin{array}{c}\text { Cumulative } \\
\text { time(s) }\end{array}$ & $\begin{array}{c}\text { Displacement } \\
(\mathrm{mm})\end{array}$ \\
\hline JZ-1 & 0.03 & 20 & 20 & 0.6 \\
JZ-2 & 0.05 & 20 & 40 & 1.6 \\
JZ-3 & 0.13 & 20 & 60 & 4.2 \\
JZ-4 & 0.185 & 20 & 80 & 7.9 \\
JZ-5 & 0.3275 & 40 & 120 & 21 \\
JZ-6 & 0.3725 & 40 & 160 & 35.9 \\
JZ-7 & 0.575 & 40 & 200 & 58.9 \\
JZ-8 & 0.713 & 30 & 230 & 80.3
\end{tabular}

Table 5 Displacement controlled program of the steady deformation mode

\begin{tabular}{ccccc}
\hline Procedure & $\begin{array}{c}\text { Velocity } \\
(\mathrm{mm} / \mathrm{s})\end{array}$ & $\begin{array}{c}\text { Duration } \\
(\mathrm{s})\end{array}$ & $\begin{array}{c}\text { Cumulative } \\
\text { time(s) }\end{array}$ & $\begin{array}{c}\text { Displacement } \\
(\mathrm{mm})\end{array}$ \\
\hline JZ-1 & 0.2667 & 45 & 45 & 12 \\
JZ-2 & 0.2 & 35 & 80 & 19 \\
JZ-3 & 0.15 & 20 & 100 & 22 \\
JZ-4 & 0.07 & 50 & 150 & 25.5 \\
JZ-5 & 0.05 & 50 & 200 & 28 \\
JZ-6 & 0.025 & 100 & 300 & 30.5 \\
JZ-7 & 0.015 & 100 & 400 & 32 \\
JZ-8 & 0.008 & 100 & 500 & 32.8 \\
JZ-9 & 0.007 & 100 & 600 & 33.5 \\
JZ-10 & 0.0035 & 200 & 800 & 34.2 \\
\hline
\end{tabular}



(a)

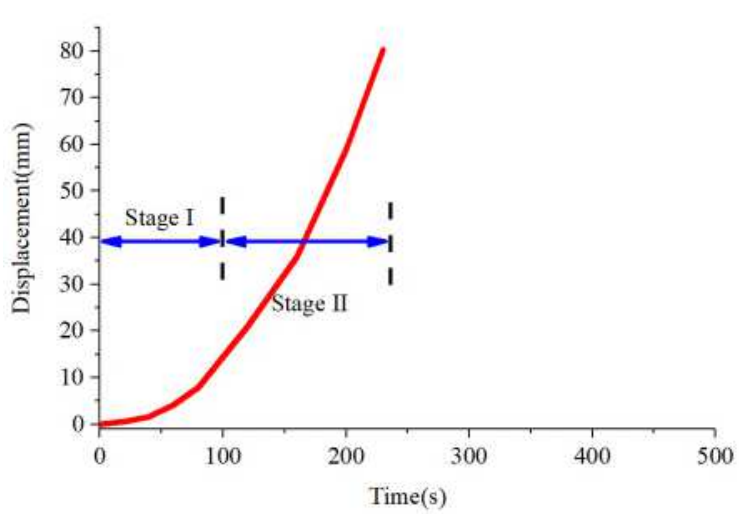

(b) 


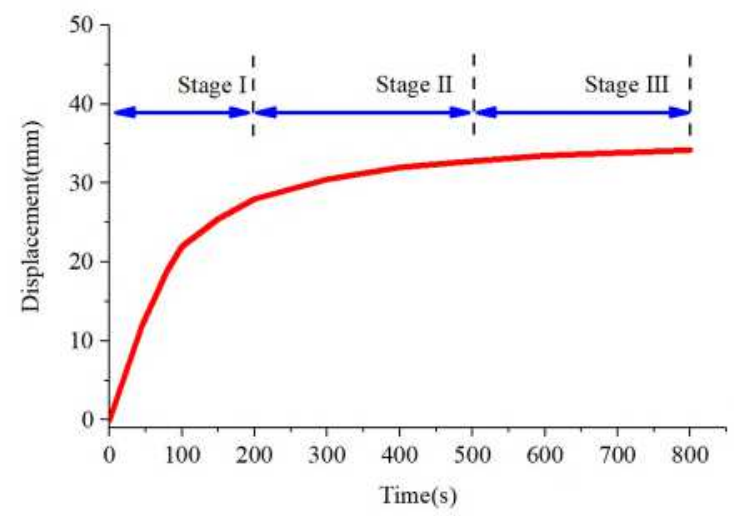

(c)

Fig. 4 Displacement-time curve(a) progressive deformation mode;(b) sudden deformation mode;(c) steady deformation mode

\section{Results and analysis}

\subsection{AE count and shear surface deformation}

Due to the shear surface deformation, thus the backfill materials undergoing deformation will generate acoustic emission signals. And the process of shear surface deformation could be judged according to the acoustic emission activities at different stages, such as the AE count or the cumulative AE count. Three different types of the deformation modes were tested to investigate the correlation between $\mathrm{AE}$ count parameters and shear surface deformation.

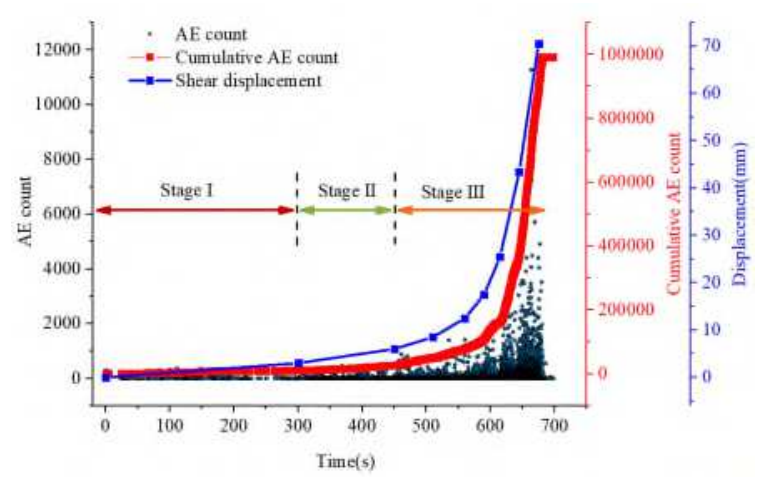

(a)

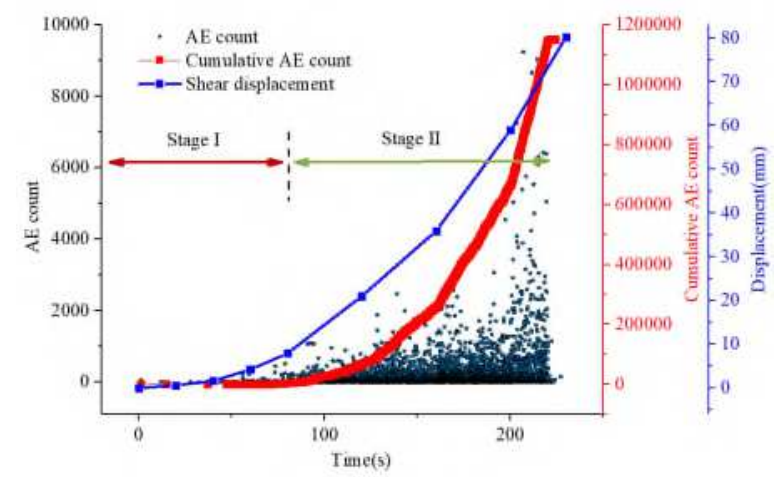

(b)

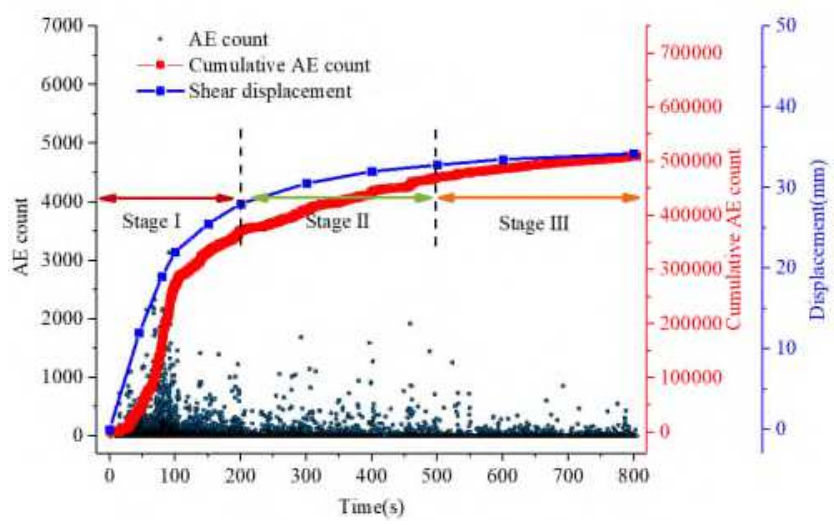

(c)

Fig. 5 The AE count, cumulative AE count and shear surface displacement for east test (a) progressive deformation mode;(b) sudden deformation mode;(c) steady deformation mode

Fig. 5 reflects the evolution characteristics of AE count and cumulative AE count for different deformation 
modes. For progressive deformation mode, the test results indicate that AE count experiences a low-level period, an active period and a rapid increase period. In the initial stage, there is small magnitude of AE count relatively, then the AE count is getting more active notably. When the shear displacement enters the later accelerating stage, the acoustic emission bursts, thus the AE count increases sharply. For the sudden deformation mode, the evolution process reaching to larger deformation is much shorter than that of progressive deformation mode. In the initial deformation stage, the acoustic emission activities are getting more active quickly. In the rapid deformation stage subsequently, the $\mathrm{AE}$ count increases sharply in a short time due to larger deformation rate, and the evolving curve of cumulative AE count rises much steeply. For the steady deformation mode case, in the initial stage with rapid deformation rate, significant deformation suddenly appears in this stage, the acoustic emission activity is quite active, and the curve of cumulative AE counts rises sharply, which is distinctive to the previous two cases. Subsequently, the deformation rate begins to decrease gradually, the number of the acoustic emission signals decreases, and the curve of cumulative AE counts slows down gradually. In the last stage with a quite tiny deformation rate, the acoustic emission activity maintains a slight low-level, and the curve of cumulative AE counts is relatively flat trend, exhibiting a "quiet period".

Besides, the Fig. 5 reflects the evolution trends of the cumulative AE count curves are very similar to the shear surface displacement. In the deformation stage with low deformation rate, the increase rate of the cumulative AE count curve is smaller. Once the deformation rate increases sharply in the later accelerating stage, the cumulative AE count curves all show the variation consistency, presenting the steep trend. The acoustic emission activity level and cumulative $\mathrm{AE}$ counts curves corresponding to different deformation modes are distinctly different, which may be crucially used as the earlier identification and further warning response for the different landslide movements.

\subsection{Evolution characteristics of AE duration-count}

As an analysis method of acoustic emission events, the correlation analysis method can demonstrate the correlation characteristics of different acoustic emission signals. In this section, the correlation diagram of $\mathrm{AE}$ duration-count is used to analyze the signal evolution process under different deformation cases. The emitted acoustic emission signal may carry different waveform parameters under difference deformation rates, through the correlation diagram of $\mathrm{AE}$ duration-count to analyze the deformation evolution characteristics, the different deformation modes can be effectively identified.



(a)



(b) 


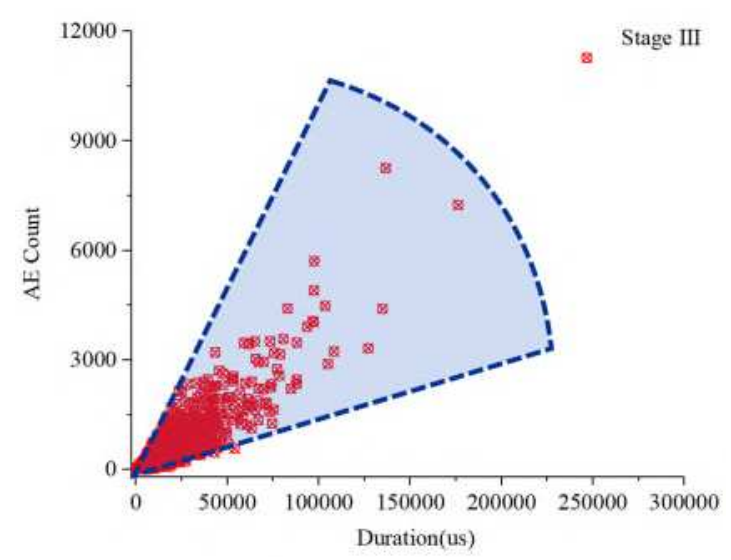

(c)

Fig. 6 Evolution process of AE duration-count under the progressive deformation modes (a) stage I, 0-300s;(b)

The Fig. 6 presents the correlation diagram of AE duration-count in the progressive deformation mode. In the initial deformation stage, the acoustic emission activity is not active, and the AE signal duration and AE count are both at low level, whereas the signal hit distribution concentrates in a relatively smaller scale. As the deformation begins to enter the accelerating stage gradually, the acoustic emission signals are accompanied by a longer duration, and the magnitude of the AE count increases simultaneously. There is a noteworthy phenomenon that the AE duration-count shows a positive correlation in a large scale, and the signal hits distribution is relatively scattered close to the later stage.

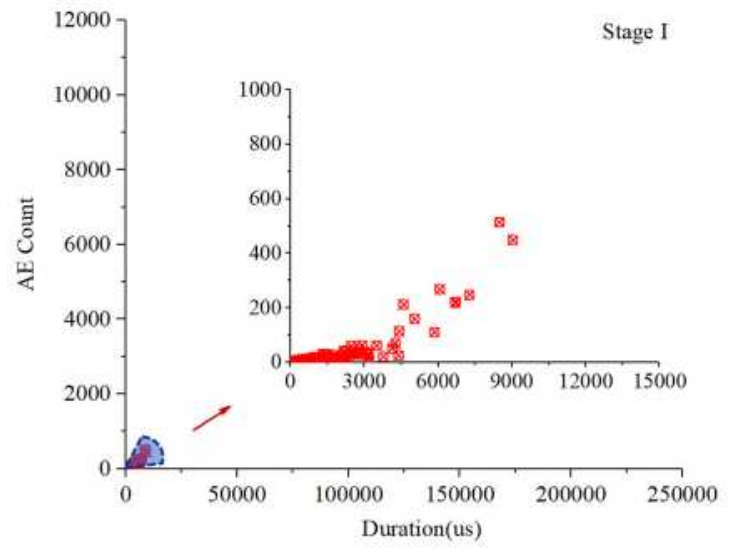

(a)



(b)

Fig. 7 Evolution process of AE duration-count under the sudden deformation mode (a) stage I, 0-80s;(b) stage II, 80-230s earlier stage, the signal duration-count concentrates only in a quite small scale, whereas the $\mathrm{AE}$ signal duration maintains a relatively low level. As the deformation rate increases rapidly in a short time, the AE signal is quite active, the signal hits distribution is getting scattered in a short time. Besides, the AE signal duration increase drastically, and there is also a positive correlation between the AE duration and count in a large scale. 


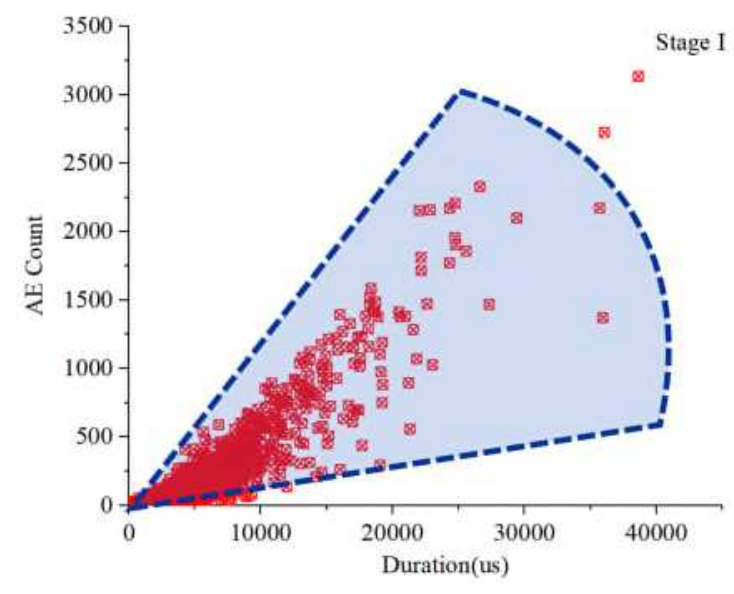

(a)

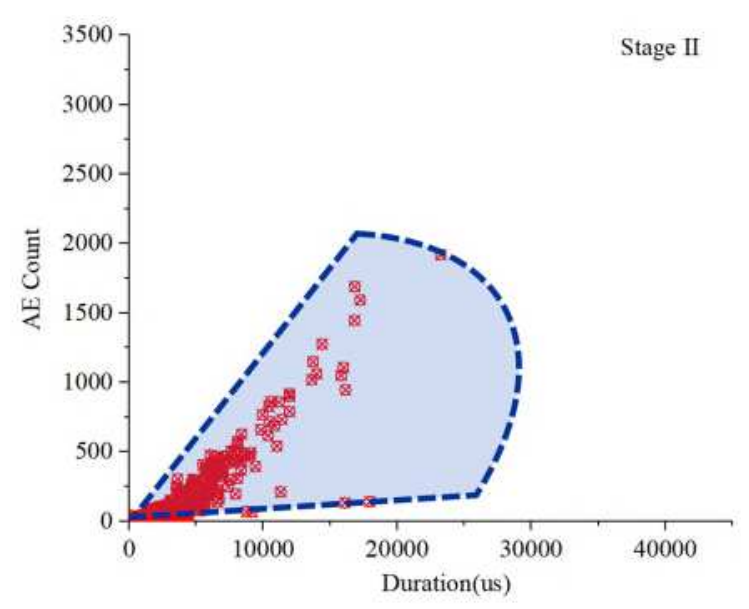

(b)

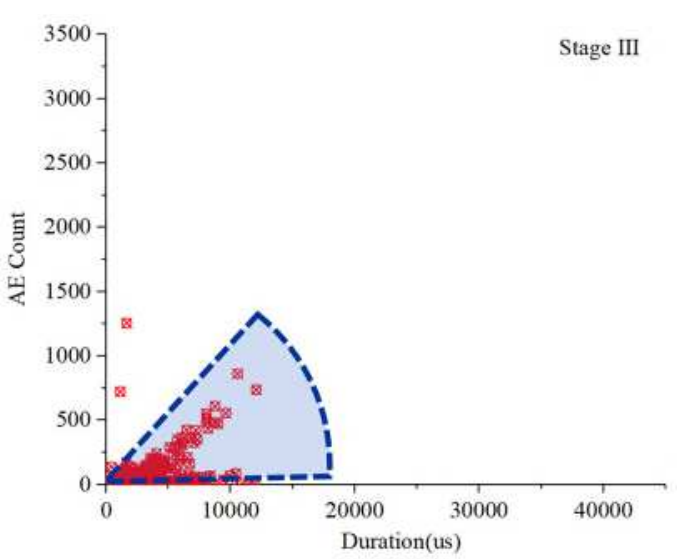

(c)

Fig. 8 Evolution process of AE duration-count under the steady deformation mode (a) stage I, 0-200s;(b) stage II 200-500s; (c) stage III, 500-800s

Fig. 8 presents the correlation diagram of AE duration-count in the steady deformation mode. In the initial stage with rapid deformation rate, lager deformation appears in this stage instantly, and the acoustic emission signal is active particularly. Besides the magnitude of AE duration and count are relatively larger, the signal hits distribution scatters relatively in a large range. Subsequently, the deformation rate gradually decreases, the evolution scale of duration-count distribution has been narrowing gradually. In the later stage with tiny deformation rate, the acoustic emission signal points are mainly concentrated in a very small scale.

\subsection{Evolution characteristics of AE amplitude-energy}



(a)

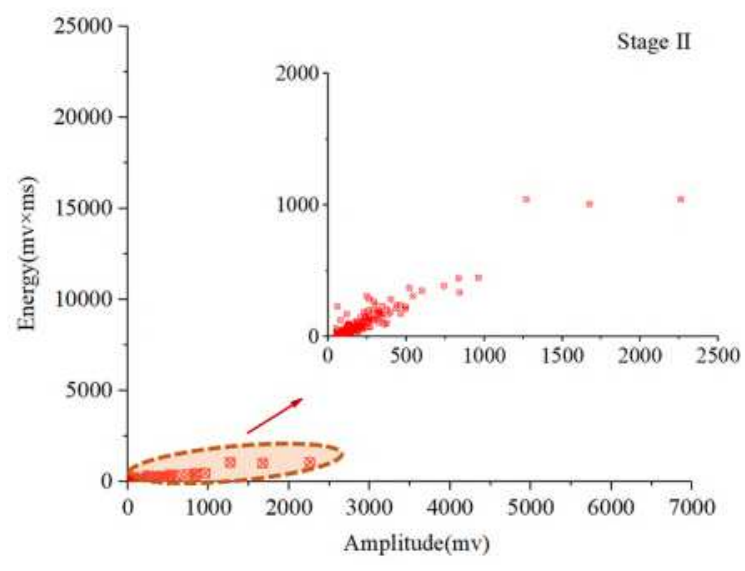

(b) 


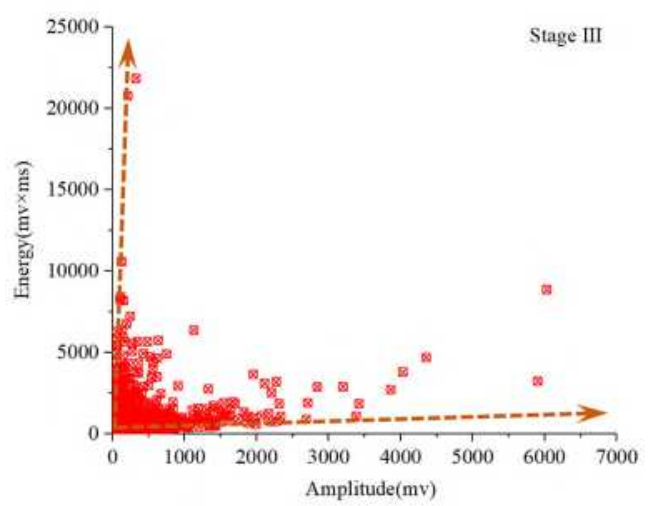

(c)

Fig. 9 Evolution process of AE amplitude-energy under the progressive deformation mode (a) stage I, 0-300s; (b) stage II, 300-450s; (c) stage III, 450-700s

Fig. 9 presents the correlation diagram of AE amplitude-energy in the progressive deformation mode. In the initial stage, the acoustic emission activity maintains at a low level, the signal amplitude and energy are both at a relatively low-level, and the signal hits distribution concentrates in a relatively small scale. As the deformation rate increase, the acoustic emission signal has a larger magnitude of AE amplitude and energy. Relatively, the amplitude-energy distribution range begins to gradually expand widely, with a large number of high-amplitude and low-energy, low-amplitude and high-energy acoustic emission signals, and there is a noteworthy phenomenon that the signal hits distribution has relatively scattered during final stage.

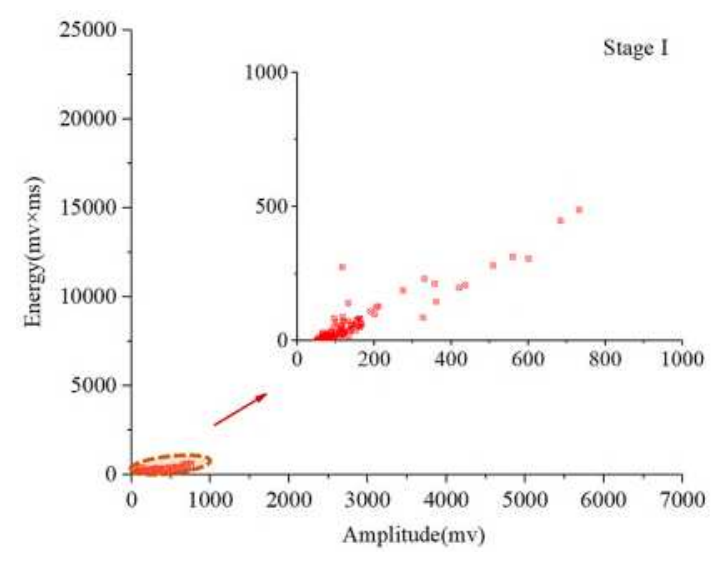

(a)

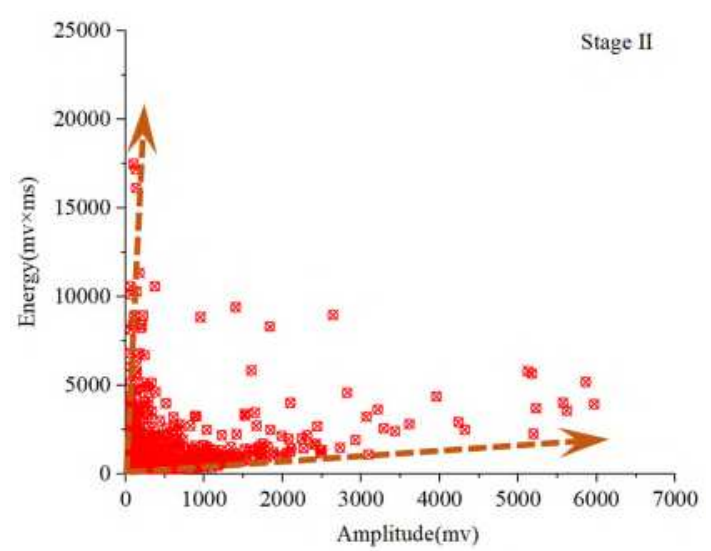

(b)

Fig. 10 Evolution process of AE amplitude-energy under the sudden deformation mode (a) stage I, 0-80s;(b) stage

$$
\text { II, 80-230s }
$$

Fig. 10 shows the correlation diagram of AE amplitude-energy in sudden deformation mode. In the initial deformation stage, the AE amplitude-energy concentrates in a relatively small scale. With the rapid increase of the deformation rate in a short time, the magnitude of $\mathrm{AE}$ amplitude and energy increases sharply. The amplitude-energy hits distribution scale increases rapidly in response to applied deformation rate, and the signal points is relatively scattered state. Besides, there are also many high-amplitude and low-energy, low-amplitude and high-energy acoustic emission signals in the rapid deformation stage. 


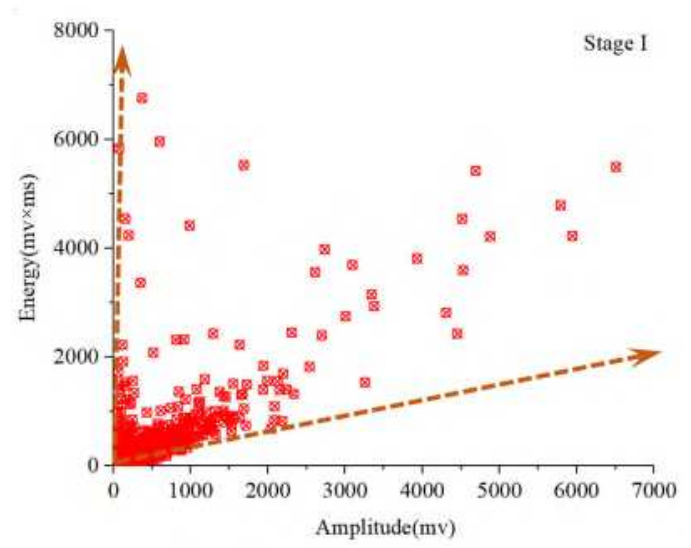

(a)



(b)



(c)

Fig. 11 Evolution process of signal amplitude- energy under the steady deformation mode (a) stage I, 0-200s;(b) stage II 200-500s; (c) stage III, 500-800s

Fig. 11 shows the correlation diagram of AE amplitude-energy in the steady deformation mode. In the early stage with rapid deformation rate, and there is significant deformation instantly. In this stage, the acoustic emission activity is quite active, and the acoustic emission signals have greater magnitude of energy and amplitude. Relatively, the amplitude-energy has a large distribution range, whereas the signal hits distribution is relatively scattered. Then the deformation rate gradually decreases, thus the acoustic emission signal amplitude and energy value both gradually decrease, and the signal distribution scale begins to decreases gradually. In the later stage with tiny deformation rate, the signal points distribution concentrates in a small scale.

\subsection{Dominant frequency characteristic}

During the process of shear surface deformation, reactions from the host soil cause the pressures along columnar backfills changes constantly, resulting in the confining pressures in the backfill to fluctuate, this behavious directly affects the frequency domain characteristics of the acoustic emission signal (Mueth et al. 1998; Blair et al. 2001; Michlmayr et al. 2013; Michlmayr et al. 2014; Ban et al. 2020). For the glass particles shearing movement, such acoustic emission probably carries the crucial information concerning variant landslides process. Thus the frequency domain characteristics may present distinction properties, and analyzing the frequency domain characteristics during the different deformation stages could identify the different landslide types, further provide a basis for the prediction of the landslide. 


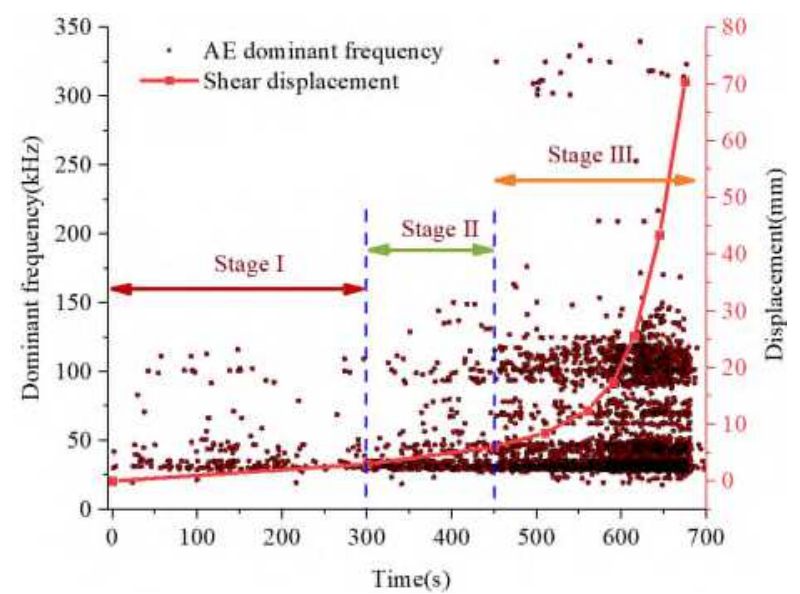

(a)

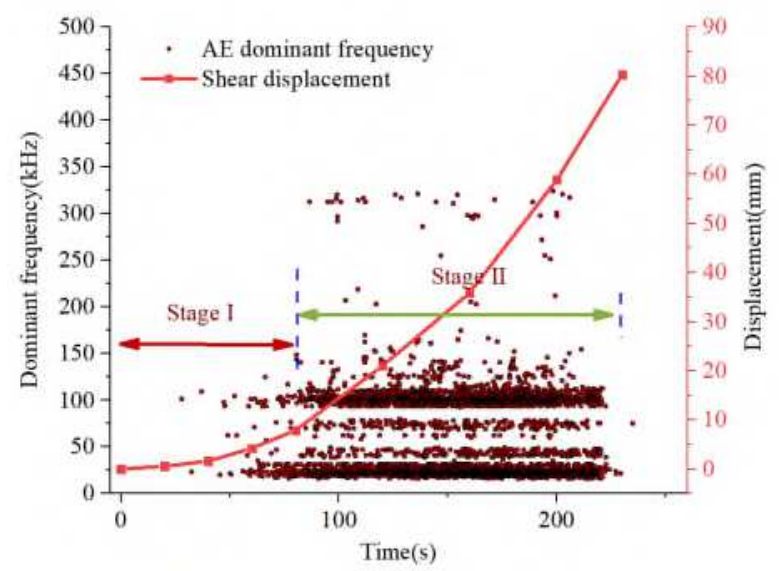

(b)

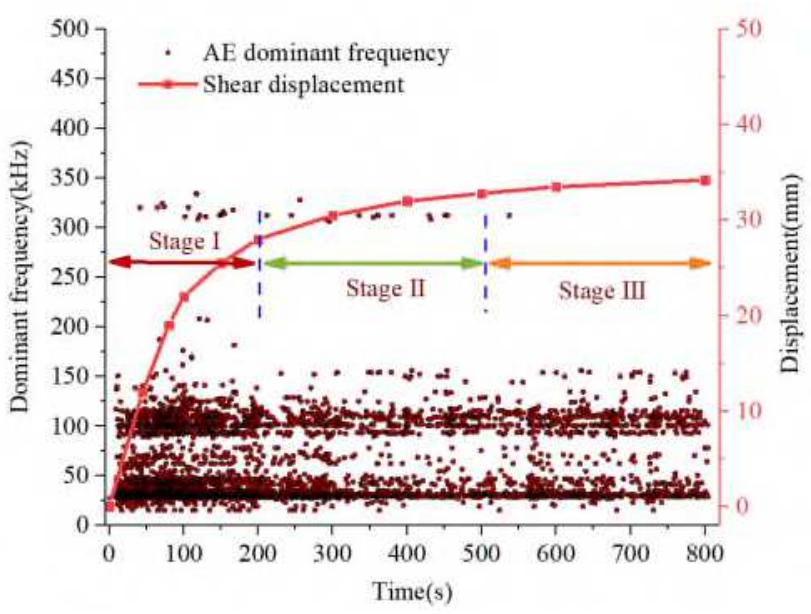

(c)

Fig. 12 The AE dominant frequency evolution and shear displacement in the entire test process(a) progressive deformation mode;(b) sudden deformation mode;(c) steady deformation mode

The dominant frequency characteristics during the shear surface deformation process under different deformation modes are showed in the Fig. 12. For the progressive deformation mode, the dominant frequency band has a small distribution range at the initial stage, and its frequency range is mainly between $25 \sim 150 \mathrm{kHz}$. Gradually the number of the acoustic signals in the dominant frequency band increases. After entering the later accelerating stage with rapid deformation rate, the signal intensity increases significantly, note that it clearly exhibits the strong tendency of serial high-frequency band distribution appearing in 300 350 kHz.

For the sudden deformation mode, in the early deformation stage, the acoustic emission signal is dominated by relatively low frequencies, with a narrow frequency domain. And its dominant frequency domain is also below $150 \mathrm{kHz}$, a small number of signal hits appear in the low dominant frequency bands. In a short time, as the deformation rate increases rapidly, the acoustic emission events begin to occur frequency contents over a wide range, and high-frequency signals appear significantly ranging from 300 350 kHz.

For the steady deformation case, the deformation rate is relatively large in the early stage, the deformation value increases sharply, and the acoustic emission signal is particularly active with high signal intensity. At this stage, some high-frequency hits with a dominant frequency into $300 \sim 350 \mathrm{kHz}$ arise earlier. As the deformation rate gradually decreases, also the number of high-frequency signal gradually decreases. In the later stage with a tiny deformation rate, there is a noteworthy phenomenon only low-frequency signals exciting, and a relatively small number of signal hits appear in this stage. During this tiny deformation stage, the frequency domain is 
below $150 \mathrm{kHz}$, and there are no high-frequency signals between 300 350 kHz appear anymore.

From the serial tests, it's found that the dominant frequency presents evolution characteristics during different shear deformation stages. When the deformation rate is slow, there are only relatively low frequency signals under $150 \mathrm{kHz}$, but no high frequency signals. These acoustic emission signals emitted are probably derived from the mutual compression of the backfill particles in this stage. As the deformation increase gradually, the column of granular backfills also deforms more, and this deformation behavior induces relatively high frequency levels of AE signal propagating along the waveguide. There is the mutual compression between the particles, also with some frictional sliding of grains, which leads to an increase in the number of acoustic emission events. When the deformation rate increases rapidly, namely getting into the accelerating deformation stage, not only the low frequency and intermediate frequency signals appear more drastically, also coupling with the continual appearance of high-frequency signals between the $300 \sim 350 \mathrm{kHz}$, which is quite distinct from that in low deformation rate stages. Probably because the host soil deformation rate accelerates, the friction force between the internal particles increases due to the high-confining stress, and thus generating intense interparticle friction. Even the high frequency signals are partially derived from the amounts of backfill particle fracture by the greater compact stress. As the consequence, these activities release the acoustic signal in the high dominant frequency.

\subsection{Energy ratio analysis}

From the above analysis, the frequency domain shows different characteristic with the shear deformation, particularly the evolutionary trend of high-frequency signals in response to the deformation behavious. By analyzing the trend of the energy proportion of high-frequency signals in different deformation stages, we further discuss correlation between the deformation modes and the energy ratio evolution of acoustic emission signal. Table 6 shows the reconstructed frequency bands signal decomposed up to the third layer after the wavelet packet decomposition, totaling 8 frequency bands.

Table 6 The frequency band range of reconstructed signal decomposed by wavelet packets

\begin{tabular}{ccc}
\hline \multicolumn{3}{c}{ Number Component Frequency domain $/ \mathrm{kHz}$} \\
\hline 1 & $(3,0)$ & $0 \sim 62.5$ \\
2 & $(3,1)$ & $62.5 \sim 125$ \\
3 & $(3,2)$ & $125 \sim 187.5$ \\
4 & $(3,3)$ & $187.5 \sim 250$ \\
5 & $(3,4)$ & $250 \sim 312.5$ \\
6 & $(3,5)$ & $312.5 \sim 375$ \\
7 & $(3,6)$ & $375 \sim 437.5$ \\
8 & $(3,7)$ & $437.5 \sim 500$
\end{tabular}

Decompose the acoustic emission signal into the third layer, it will generate $2^{3}$ component signals, thus one of the component signals is denoted as $S_{3 j}$, and it contains the correspond energy $E_{3 j}$, thus:

$$
E_{3 j}=\left|\int S_{3 j}\right|^{2} d t=\sum_{k=1}^{m}\left|x_{j k}\right|^{2}
$$

Where: $x_{j k}\left(j=1,2, \mathrm{~L}, 2^{3} ; k=1,2,3 \mathrm{~L}, m\right)$ represents the amplitude of the discrete point in reconstructed signal $S_{3 j}, m$ is the number of discrete sampling points of the acoustic signal.

Obviously, the total energy of the decomposed signal is calculated by the following equation: 


$$
E_{0}=\sum_{j=1}^{2^{3}} E_{3 j}
$$

$P_{j}$ is the energy percentage of each sub-band of the acoustic signal, and can be written as:

$$
P_{j}=\frac{E_{3 j}}{E_{0}} \times 100 \%
$$

According to formula (4) (6), the energy percentage of the frequency band component can be calculated, so as to accurately analyze the frequency band energy properties of the acoustic emission signal under the different deformation modes.

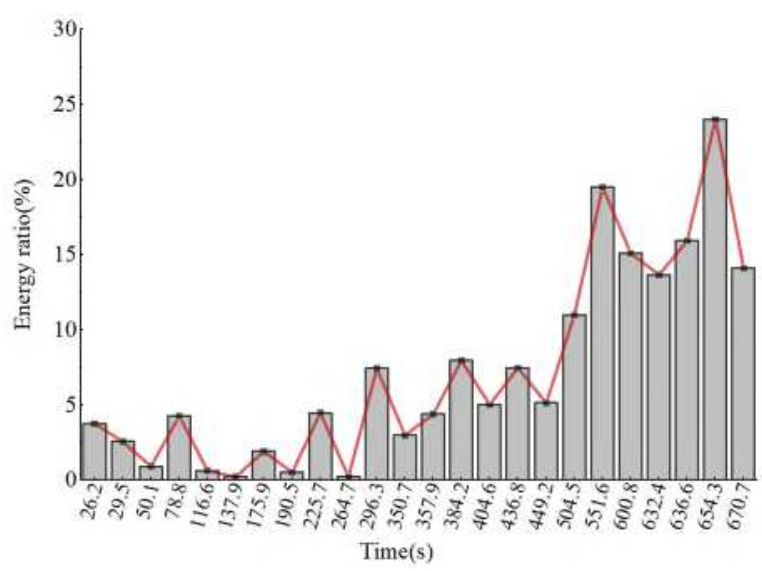

(a)

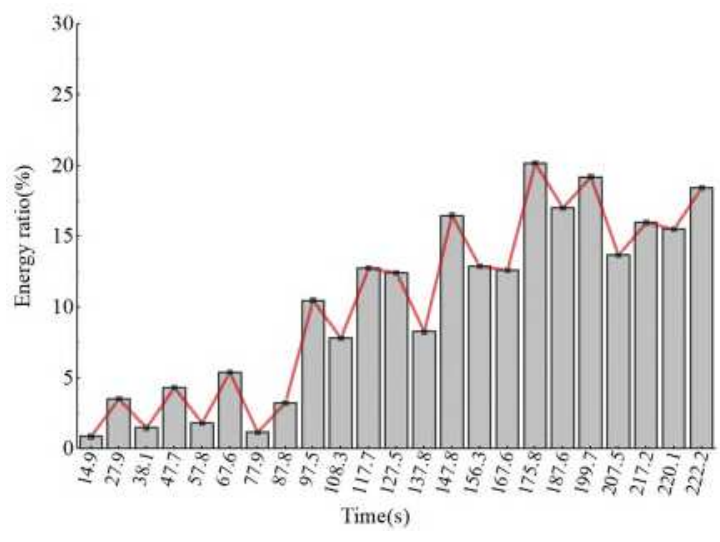

(b)

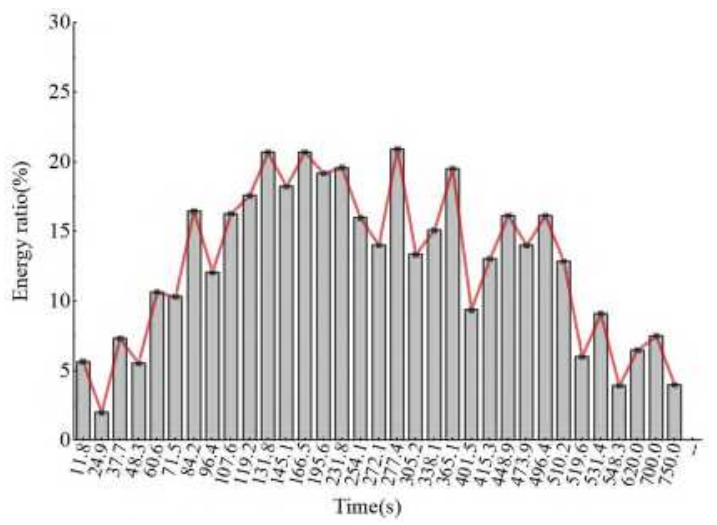

(c)

Fig. 13 Energy ratio of the high frequency band against time(a) progressive deformation mode;(b) sudden deformation mode; (c) steady deformation mode

Fig. 13 presents the statistical trend of the energy percentage of the high frequency band between $312.5 \sim 500$ $\mathrm{kHz}$ in different deformation modes. For the progressive deformation case, it is noteworthy that the energy proportion significantly increases with the shear sliding deformation. In the initial period, the energy proportion exhibits the relatively minimum value, not exceeding 5\%; as the deformation rate increases, the high-frequency energy ratios tend to increase, and the proportion value has a certain rise greater than $5 \%$; During deformation accelerating stage, the energy proportion of high-frequency signals increases significantly, and the energy proportion is around $20 \%$, or even higher. For the sudden deformation mode, the high-frequency signal energy proportion increases significantly with the rapid increase of the deformation rate, and the magnitude of energy proportion is around $20 \%$ close to the later accelerating stage. For the steady deformation mode, the deformation rate is large in the rapid deformation stage early, and the energy proportion of high-frequency signal increases 
rapidly. However, as the deformation rate gradually decreases later, the energy proportion of high-frequency begins to decrease. At last the tiny deformation stage, the proportion of high-frequency energy is at a relatively low-level. Noteworthily, the proportion of high-frequency energy has experienced a process of the rapid increase firstly and then the gradual decrease in response to the deformation behavious.

It follows that the physical interaction variation between the backfills particles appears during the different deformation stages, which will lead to the energy proportion evolution of the acoustic emission signal emitted. To some extent, this statistical energy proportion can be used as identification and monitoring methods, to alert the user that the soil slope has deformed in which condition, from a low displacement rate to a high magnitude, or from a high rate then to a low rate, further to be used in landslide modes recognition and risk management, it is critical to enhance predictability and early warning precision.

\section{Discussion}

A shear model was developed to perform the different landslide failure by simulating the shear surface deformation modes. A series of tests have been performed to subject the waveguide under the conditions of the shear failure process. The different deformation modes of the shear surface were automatically controlled by the set program of the CMT-5205 servo machine. This study mainly focuses on the AE detection evolution response to the different displacement-time relation of the soil landslides, mainly includes: progressive deformation mode, sudden deformation mode and the steady deformation mode. And the different shear surface deformations were controlled by the serve displacement rate program. Some key monitoring parameter of the AE signals, such as the AE count, cumulative AE count, duration time, amplitude, energy, frequency domain, were obtained through experiments to investigate the corresponding relationships of the AE detection evolution and shear deformation parameters. It's found that there is the strong correlational relationship of shear surface displacement with the cumulative AE count curve, which provides that the cumulative AE count curve is effectively indicative of sliding displacement, the most previous research about the early landslide warning all investigates correlational relationship between the AE rate and the sliding displacement (Wang et al. 2009; Dixon et al. 2015 ; Deng et al. 2019; Smith et al. 2017; Smith et al. 2014).

The test results show that evolution characteristics of acoustic emission are difference in response to the applied shear deformation modes. For the progressive mode, the low deformation rate maintains for greater time magnitudes in early stages, thus the smaller AE count continues a long time until the accelerating deformation stage, the number of AE count starts to increase rapidly. For the sudden mode, the AE count presents a rapid growth trend in a short time, and the curve of cumulative AE count rises rapidly over time. For the steady mode, the $\mathrm{AE}$ count increases sharply in initial stage, as the deformation rate gradually decreases, the AE count gradually decreases, showing a distinction trend of rapid increase firstly and then gradual decrease.

In addition, for the signal hits distribution characteristic of $\mathrm{AE}$ duration-count and amplitude-energy correlation, for the both of progressive mode and sudden mode, the AE hits distribution presents the evolution process form the concentrated hits distribution in the small scale early to the scattered hits distribution in large scale relatively in the later accelerating deformation stage, distinctively the evolution process experiences a quite short time for the sudden mode. For the steady mode, however, the signal scattered distribution gradually evolves into a concentrated small-scale distribution in response to applied deformation behavior over time. The evolutionary transformation tendency from the small-range to large-range, or from large-range to small-range, indicates that landslide movement is undergoing different deformation states. These results demonstrate that signal points distribution of $\mathrm{AE}$ duration-count and amplitude-energy appears to be correlation with the 
deformation movement states, this information can provide identification information and early detection of deformation evolution behavious that soil slopes experience during landslide movement process.

Besides, Fig. 14 15 focus on the evolution process of the AE detection amplitude and duration parameters. The AE amplitude and $\mathrm{AE}$ duration are integrated as an identification indicator to understand the overall deformation behavior of slope movements, which reveals relevant evolution characteristics to different deformation modes.
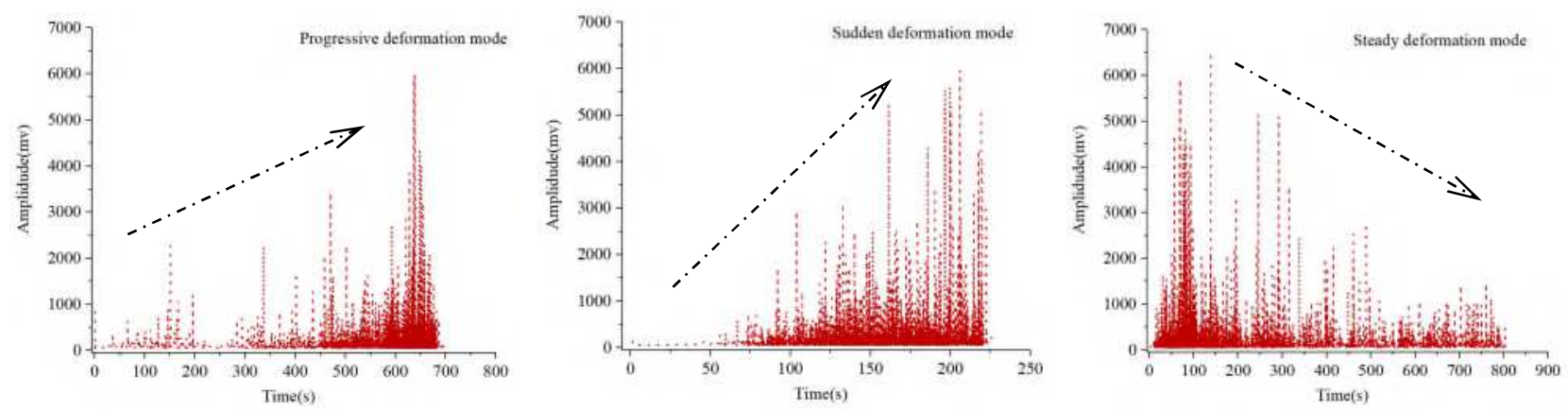

Fig. 14 Evolution characteristics of AE amplitude in different deformation modes(a) progressive deformation mode;(b) sudden deformation mode;(c) steady deformation mode
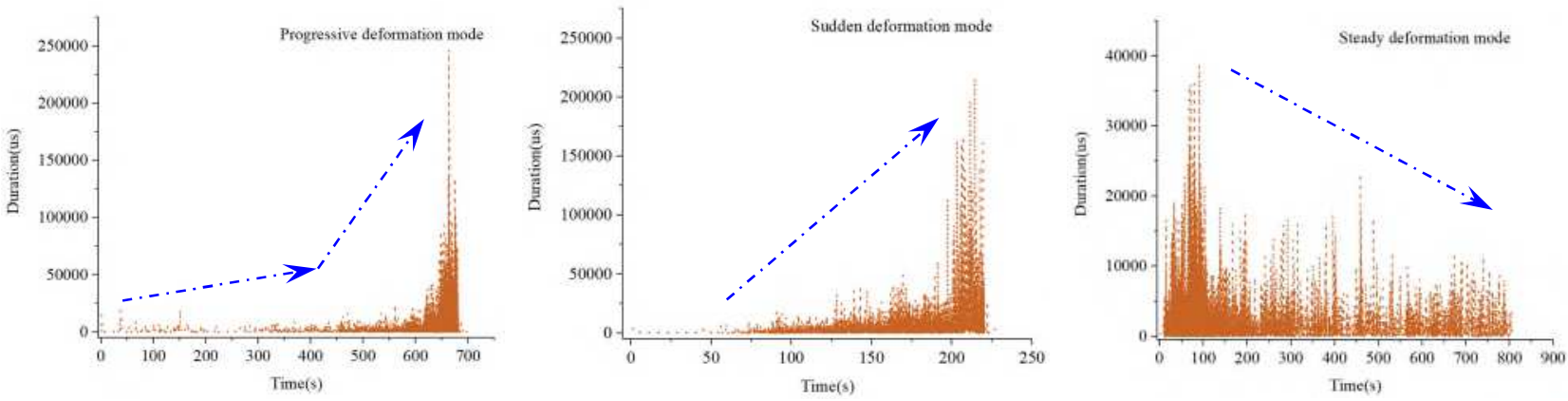

Fig. 15 Evolution characteristics of AE duration in different deformation modes(a) progressive deformation mode;(b) sudden deformation mode;(c) steady deformation mode

It is clear that both the $\mathrm{AE}$ detection amplitude and duration evolutions experience a low-level period, an active period and a rapid increase period in progressive deformation mode. For the sudden deformation mode, the evolution time from a low magnitude to a high magnitude is often much shorter than that of a progressive deformation mode. For the steady deformation mode, in the initial rapid deformation stage, the magnitude of both $\mathrm{AE}$ amplitude and duration parameters is larger, as the deformation rate gradually decreases, the parameters magnitude shows a decay trend, smaller than that in the previous stage. These AE detection parameters increase to the relatively larger magnitude during the monitoring process, revealing that the landslide deformation rate is getting larger, probably leading to the soil slope entering a dangerous period.

Overall, few studies have focused on the frequency domain characteristic relevant to deformation evolution stages of landslide failures directly. By analyzing the frequency domain evolution characteristics of the AE signals during the different deformation stages, the results demonstrate that the frequency domain characteristic is a good discriminant indicator identifying the deformation stage, which has the distinct perception characteristic.

According to the frequency domain indicator of the AE detection signals, which is closely related to the shear deformation modes, especially in the accelerating deformation stage, it may directly determine whether the soil slope is during the rapid deformation stage. Frequency domain has the promising potential to become an efficient early warning indicator for such failures. For instance, during the shear deformation stage with rapid deformation rate, not only the low frequency and intermediate frequency signals appear more drastically, also the continual 
appearance of high-frequency signals between the $300 \sim 350 \mathrm{kHz}$. This high-frequency signals phenomenon in the accelerating stage is quite distinct from the low deformation rate stage. When the shear deformation rate appears larger magnitude, note that there is wide frequency band with high-frequency signal hits. Once the deformation rate gradually decreases, the number of high-frequency signals gradually decrease, or even high-frequency signals disappear correspondingly.

As the sliding soil mass begins to move, glass granular shearing takes place within the active waveguide at the shear surface. Under the rapid deformation rate, as the active waveguide resists shear and bending, the backfill deforms around the waveguide. The reactions from the host soil cause the pressures along the active waveguide to increase. Reactions from both the host soil and the waveguide cause the confining pressures in the backfill to increase, this behaviour causes the intensively interparticle friction, even the particles fracture, emitting the high frequency AE signals. This finding can contribute to identify the rapid landslide deformation and further improve slope earning management. Furthermore, it is noteworthy that the energy proportion of the high-frequency band in the range of $312.5 \sim 500 \mathrm{kHz}$ significant increases with the rapid shear deformation. For both progressive deformation mode and sudden mode, the energy proportion of high-frequency signal shows an increasing trend, and the energy proportion occupies to approximately $20 \%$ close to the late stage with rapid deformation rate. Just the evolution process of sudden mode up to the high energy proportion is much faster than the progressive mode. For the steady mode, however, the proportion of high-frequency energy has experienced the evolution trend with rapid increase firstly and then gradual decrease.

In summary, different $\mathrm{AE}$ detection parameter indexes can be utilized for the landslides movement identification and monitoring, in this study, the AE count, cumulative AE count, duration-count scattergram, amplitude-energy scattergram, dominant frequency characteristic, energy proportion of high-frequency signals overall process are explored to identify the evolution process of the different deformation modes. Specifically, we summarize the evolution characteristics of AE detection parameters during different deformation modes, as shown in Table 7.

Table 7 Comparison of AE detection parameters with different deformation modes

\begin{tabular}{cccc}
\hline $\begin{array}{c}\text { AE detection evolution } \\
\text { characteristic }\end{array}$ & $\begin{array}{c}\text { Progressive deformation } \\
\text { mode }\end{array}$ & Sudden deformation mode & Steady deformation mode \\
\hline AE count rate & Low-level $\rightarrow$ High level & Low-level $\rightarrow$ High level & Rapidly \\
Gradually & High level $\rightarrow$ Low-level \\
Curve of the cumulative AE & Gently increasing $\rightarrow$ Slowly \\
count & increasing $\rightarrow$ Sharply & Sharply increasing & Sharply increasing $\rightarrow$ Slowly \\
increasing & increasing $\rightarrow$ Gently increasing \\
AE duration-count & Small scale $\rightarrow$ Large scale & Small scale $\rightarrow$ Large scale & \\
characteristics & Gradually & Rapidly & Large scale $\rightarrow$ Small scale \\
AE amplitude-energy & Concentration $\rightarrow$ Scatter & Concentration $\rightarrow$ Scatter & Scatter $\rightarrow$ Concentration \\
characteristics & Gradually & Rapidly & High-frequency $\rightarrow$ \\
Dominant frequency & Low-frequency $\rightarrow$ & Low-frequency $\rightarrow$ & Low-frequency \\
characteristic & High-frequency & High-frequency & Sharply increasing \\
Energy proportion of & Gradually increasing & Sharply increasing & Gradually decreasing \\
high-frequency signals & Low-level $\rightarrow$ High level & Low-level $\rightarrow$ High level & High level $\rightarrow$ Low-level
\end{tabular}






Fig. 16 Generalized geological model for probable landslide modes(a) progressive landslide mode;(b) sudden

For the general steep slope with loose soil or gravel soil subject to continuous long-term rainfall, if the typical AE parameters, such as the count rate, amplitude, duration, present the trend from low level to the high level gradually in a long time, and the correlation duration-count and amplitude-energy scattergrams both extend to large scale gradually, notably when the relatively high frequency signals appear constantly, the progressive landslide instability will possibly occur.

For high-steep slope with siltized intercalations underneath the sliding mass, impacted by the triggering conditions of slope toe excavation, heavy rainstorm or earthquake, once the magnitude of $\mathrm{AE}$ parameters all increase from the low level to the high level rapidly in a short time during the process of monitoring, and the correlation scattergrams show the tendency of scattered expansion rapidly, also the relatively high frequency signals appear intensively with high energy proportion, then the slope failure is about to occur, presenting the sudden landslide mode.

Conversely, for gentle terrain underneath the soft layer potentially affecting by fluctuation of reservoir water level, when the AE count, amplitude, duration present the trend of a rapid increase firstly and then a gradual decrease with the time, and these correlation diagram hits distribution scatters firstly and then the signal hits distribution begins to concentrate, also the number of high-frequency signal gradually decreases or disappear, the cumulative $\mathrm{AE}$ counts curve begins to maintain relatively flat trend, thus the possibility of the occurrence of steady landslide mode will be high, the slope probably does not occur instable failure.

The instability process of soil slope is complicated and can be influenced by many factors, such as geological conditions, hydrological conditions, geotechnical properties. In the natural field situation, just based on few AE detection parameter characteristics, it is indeed difficult and unrealistic to judge the deformation stage of different landslide movements, to accurately identify ultimate sliding deformation mode. Through the analysis processing of continuous AE monitoring data, we can obtain important identifications reference by synthetic application of these $\mathrm{AE}$ detection evolution characteristics, comprehensive use of multiple features can help to improve the accuracy of landslide deformation stage, thus we can identify landslide deformation patterns more accurately, which is significance to the early landslide warning. An integrated discriminant criterion based on multiple AE features may be a promising method of guiding slope evolution modes monitoring.

Generally, the slope instability and collapse does not occur instantly, but through accumulation of unstable influencing factors in a certain period, slope sliding movement experiences an evolutionary process from continuous deformation to final failure. Specific grasp of the overall deformation magnitude, deformation rate and 
deformation evolution trend of the soil slope sliding in different evolution period is essential to identify landslide modes and predict soil slope failure early. Considering the natural slopes with more complex geological conditions, these $\mathrm{AE}$ detection evolution characteristics can be used as a guide for on-site monitoring methods.

539 Further research is required to apply these methods to field monitoring strategy, sending the monitoring information to the relevant geological management department so that geologists can take relevant measures, thus a sensitive, continuous, remote and real-time monitoring system pattern based on multiple AE features may be developed in the future for the identification reference and early warning of different landslide modes. Furthermore, combining with other monitoring parameters, such as displacement, rainfall, pore water pressure, cracking and sliding velocity, a monitoring and early warning platform for landslide disasters can be established based on multi-source heterogeneous monitoring data, to effectively improve the identification and early warning accuracy for landslide geological disaster.

\section{Conclusions}

In this paper, a model test for reproducing the typical shear surface deformation was designed, the displacement, $\mathrm{AE}$ data, AE correlation diagram, and the corresponding frequency domain characteristics were obtained through experiments with different deformation modes. The evolutionary characteristics of AE detection and possible precursors were analyzed, the primary conclusions are drawn:

(1) In response to applied deformation behaviours, the relationship between the shear deformation and cumulative $\mathrm{AE}$ count demonstrates strong consistency. Once the deformation increases sharply in the accelerating stage, the cumulative AE count curve shows a steeply upward trend. For the progressive deformation mode, the AE count experiences a low-level period, an active period and a rapid increase period gradually. For the sudden deformation mode, the AE count increases sharply, and the cumulative AE count curve rises much steeply. For the steady deformation mode case, the acoustic emission activity is quite active in the early stage, and the cumulative AE count curve rises sharply in the initial stage. Subsequently, the acoustic emission activity maintains a relatively low level, the cumulative AE count curve shows a relatively flat trend.

(2) For the progressive deformation and sudden deformation mode, correlation hits distribution of the AE duration-count and amplitude-energy concentrated in a relatively small scale in the initial stage with low deformation rate. The signal hits distribution becomes relatively scattered and expands into a large scale as the deformation rate increases. For the sudden deformation mode, the evolution period towards scattered signal hits distribution is much shorter than that of progressive deformation mode. Distinctive to the previous two cases, the correlation hits distributions are relatively scattered in a large range firstly, then the signal hits distribution begins to narrow gradually, at last, the signal points distribution is relatively concentrated in a very small scale.

(3) The AE signal detection during the applied movement process of different deformation modes exhibits evolution characteristics as for the dominant frequency domain. Under the rapid deformation rate, not only the number of the low frequency and intermediate frequency signals increases drastically, while the continuous high frequency signals also significantly increase. For the progressive and the sudden deformation modes, the frequency domain presents low frequency signals firstly then other additional high frequency. In contrast, for the steady case, series high-frequency signal hits occur in the early stage, while there are no high-frequency signals appear anymore over time. The evolution pattern of high frequency domain may be effective indexes for different landslides, indicating that the landslide may be about to enter a rapid deformation stage. 
found that in the initial deformation stage, the energy proportion is relatively smaller. It's worth noting that the energy proportion of the high-frequency signals increases significantly during the rapid deformation stage, and the energy proportion occupies up to approximately $20 \%$ close to the later stage. For the steady deformation mode, the energy proportion of high-frequency signal increases to a larger value rapidly in the initial stage. The energy proportion of high-frequency begins to decrease, experiencing a process of a rapid increase firstly and then a gradual decrease over time as the deformation rate gradually decreases. Note that the energy proportion parameter of the high frequency band has the potential to be used as the identifying reference to the risk management of the landslide early monitoring.

\section{Acknowledgements}

This work was carried out with support from the open project (LNTCCMA-20200103; LNTCCMA-20200112) from Key Laboratory of New Technology for Construction of Cities in Mountain Area (Chongqing University), Ministry of Education

Author information

\section{Affiliations}

School of Civil Engineering, Chongqing University, No. 174 Shazheng Road, Chongqing 400030, China

College of River and Ocean Engineering, Chongqing Jiaotong University, No. 66 Xuefu Road, Chongqing

Technology Innovation Center of geohazards automatic monitoring, Ministry of Natural Resources,

\section{Contributions}

(a) Qiang Xie, Zhihui Wu contributed to investigation, methodology, writing original draft, writing-review \& editing. (b) Yuxin Ban, Zhilin Cao, Xiang Fu contributed to data curation, supervision, visualization. (c) Bolin

Ethics declarations

\section{Conflicts of interest}

The authors declare that they have no conflict of interest.

\section{References:}

Ban YX, Fu X, Xie Q (2020) Revealing the laminar shale microdamage mechanism considering the relationship 
between fracture geometrical morphology and acoustic emission power spectrum characteristics. Bulletin of Engineering Geology and the Environment 79(2): 1083-1096.

Berg N, Smith A, Russell S, Russell S, Dixon N, Proudfoot D, Take WA (2018) Correlation of acoustic emissions with patterns of movement in an extremely slow-moving landslide at Peace River, Alberta, Canada. Canadian Geotechnical Journal 55(10): 1475-1488.

Blair DL, Mueggenburg NW, Marshall AH, Jaeger HM, Nagel SR (2001) Force distributions in three-dimensional granular assemblies: Effects of packing order and interparticle friction. APS Phys. Rev. E 63(4), 041304.

Chae BG, Park HJ, Catani F, Simoni A, Berti M (2017) Landslide prediction, monitoring and early warning: a concise review of state-of-the-art. Geoences Journal 21(6): 1033-1070.

Chen P, Lu N, Formetta G, Godt JW, Wayllace A (2018) Tropical Storm-Induced Landslide Potential Using Combined Field Monitoring and Numerical Modeling. Journal of geotechnical and geoenvironmental engineering 144(11).

Chichibu A, Jo K, Nakamura M, Goto T, Kamata M (1989) Acoustic emission characteristics of unstable slopes. Acoustic Emission 8(4): 107-112.

Chowdhuri I, Pal SC, Chakrabortty R, Malik S, Das B, Roy P (2021) Torrential rainfall-induced landslide susceptibility assessment using machine learning and statistical methods of eastern Himalaya. Natural Hazards 107(1): 697-722.

Conte E, Donato A, Troncone A (2017) A simplified method for predicting rainfallinduced mobility of active landslides. Landslides 14(1): 35-45.

Conte E, Troncone A. (2012) Simplified Approach for the Analysis of Rainfall-Induced Shallow Landslides. Journal of Geotechnical \& Geoenvironmental Engineering 138(3): 398-406.

Crosta GB, Agliardi F (2003) Failure forecast for large rock slides by surface displacement measurements. Canadian Geotechnical Journal 40(1): 176-191.

Deng LZ, Yuan HY, Chen JG, Sun ZH, Fu M, Zhou YL, Yan S, Zhang ZW, Chen T (2019) Experimental investigation on progressive deformation of soil slope using acoustic emission monitoring. Engineering Geology 261,105295.

Dikshit A, Satyam DN, Towhata I (2018) Early warning system using tilt sensors in Chibo, Kalimpong, Darjeeling Himalayas, India. Natural Hazards 94: 727-741.

Dixon N, Hill R, Kavanagh J (2003) Acoustic emission monitoring of slope instability: Development of an active wave guide system. Geotechnical Engineering 156(2): 83-95.

Dixon N, Spriggs MP (2007) Quantification of slope displacement rates using acoustic emission monitoring. Canadian Geotechnical Journal 44(8): 966-976.

Dixon N, Spriggs MP, Smith A, Meldrum P, Haslam E (2015) Quantification of reactivated landslide behaviour using acoustic emission monitoring. Landslides 12(3): 549-560.

Fan XM, Juang CH, Wasowski J, Huang RQ, Xu Q, Scaringi G, van Westen C, Havenith HB (2018) What we have learned from the 2008 Wenchuan Earthquake and its aftermath: A decade of research and challenges. Engineering Geology 241: 25-32.

Fan X, Zhan W, Dong X, van Westen C, Xu Q, Dai L, Yang Q, Huang R, Havenith H (2018) Analyzing successive landslide dam format ion by different triggering mechanisms: The case of the Tangjiawan landslide, Sichuan, China. Engineering Geology 243: 128-144.

Gance J, Malet JP, Dewez T, Travelletti J (2014) Target detection and tracking of moving objects for 
characterizing landslide displacements from time-lapse terrestrial optical images. Engineering Geology 172: 26-40.

Giri P, Ng K, Phillips W (2018) Laboratory simulation to understand translational soil slides and establish movement criteria using wireless IMU sensors. Landslides 15, 2437-2447.

Hu XL, Tan FL, Tang HM, Zhang GC, Su AJ, Xu C, Xiong CR (2017) In-situ monitoring platform and preliminary analysis of monitoring data of Majiagou landslide with stabilizing piles. Engineering Geology 228: 323-336.

Huang, BL, Yin Yp, Du CL. (2016). Risk management study on impulse waves generated by Hongyanzi landslide in Three Gorges Reservoir of China on June 24, 2015. Landslides 13(3): 603-616.

Huang RQ (2009) Some catastrophic landslides since the twentieth century in the southwest of China, Landslides 6: $69-81$.

Huang RQ, Fan XM (2013) The landslide story, Nature Geoscience 6(5): 325-326.

Huang XH, Guo F, Deng ML, Yi W, Huang HF (2020) Understanding the deformation mechanism and threshold reservoir level of the floating weight-reducing landslide in the Three Gorges Reservoir Area, China. Landslides 172879-2894.

Hungr O, Leroueil S, Picarelli L (2014) The Varnes classification of landslide types, an update. Landslides 11: 167-194.

Ju NP, Huang J, He CY, Van Asch TWJ, Huang RQ, Fan XM, Xu Q, Xiao Y, Wang J (2020) Landslide early warning, case studies from Southwest China, Engineering Geology 279: 105917.

Koerner RM, McCabe WM, Lord AE (1981) Acoustic emission behaviour and monitoring of soils. In Acoustic emission in geotechnical practice, ASTM STP 750, West Conshohocken, PA, USA: ASTM International, pp 93-141.

Li CD, Fu ZY, Wang Y, Tang HM, Yan JF, Gong WP, Yao WM, Criss RE (2019) Susceptibility of reservoir-induced landslides and strategies for increasing the slope stability in the three Gorges Reservoir Area: Zigui Basin as an example. Engineering Geology 261: 105279.

Li HJ, Xu Q, He YS, Deng JH. (2018) Prediction of landslide displacement with an ensemble-based extreme learning machine and copula models. Landslides 15: 2047-2059.

Michlmayr G, Cohen D, Dain O (2013) Shear-induced force fluctuations and acoustic emissions in granular material. Journal of Geophysical Research Solid Earth 118(12): 6086-6098.

Michlmayr G, Cohen D, Dani O (2012) Sources and characteristics of acoustic emissions from mechanically stressed geologic granular media - A review. Earth-Science Reviews 112(3-4): 97-114.

Michlmayr G, Dain O (2014) Mechanisms for acoustic emissions generation during granular shearing. Granular Matter 16(5): 627-640.

Milaghardan AH, Abbaspour RA, Khalesian M (2020) Evaluation of the effects of uncertainty on the predictions of landslide occurrences using the Shannon entropy theory and Dempster-Shafer theory. Natural Hazards 100(1): 49-67.

Mueth DM, Jaeger HM, Nagel SR (1998) Force distribution in a granular medium. APS Phys. Rev. E 57(3): 3164-3169.

Pecoraro G, Calvello M, Piciullo L (2019) Monitoring strategies for local landslide early warning systems. Landslides 16, 233-234.

Petley DN, Allison RJ (1997) The mechanics of deep-seated landslides. Earth Surface Processes and Landforms 
22(8): 747-758.

Saito M (1965) Forecasting the time of occurrence of a slope failure. Proceedings of the 6th International Conference on Soil Mechanics and Foundation Engineering, Pergamon 537-541.

Saito M, Uezawa H (1961) Failure of soil due to creep. Proceedings of the 5th International Conference on Soil Mechanics and Foundation Engineering, Paris, 315-318.

Shiotani T (2006) Evaluation of long-term stability for rock slope by means of acoustic emission technique. NDT\&E International 39: 217-228.

Smith A, Dixon N (2015) Quantification of landslide velocity from active waveguide-generated acoustic emission. Canadian Geotechnical Journal 52(4): 413-425.

Smith A, Dixon N, Fowmes GJ (2017) Early detection of first-time slope failures using acoustic emission measurements: large-scale physical modelling. Geotechnique 1-15.

Smith A, Dixon N, Meldrum P, Haslam E, Chambers J (2014) Acoustic emission monitoring of a soil slope: comparisons with continuous deformation measurements. Géotechnique Lett 4(4): 255-261.

Tiwari B, Pradel D, Ajmera B, Yamashiro B, Khadka D (2018) Landslide Movement at Lokanthali during the 2015 Earthquake in Gorkha, Nepal. Journal of Geotechnical \& Geoenvironmental Engineering 144(3).

Vadivel S, Sennimalai CS. (2019) Failure Mechanism of Long Runout Landslide Triggered by Heavy Rainfall in Achanakkal, Nilgiris, India. Journal of Geotechnical and Geoenvironmental Engineering 145(9): 1-14.

Wang BJ, Li K, Shi B, Wei GQ (2009) Test on application of distributed fiber optic sensing technique into soil slope monitoring. Landslides 6(1): 61-68.

Wang WD, Li JY, Qu X, Han Z, Liu P (2020) Prediction on landslide displacement using a new combination model: a case study of Qinglong landslide in China. Natural Hazards 96(3): 1121-1139.

Xu Q (2012) Theoretical studies on prediction of landslides using slope deformation process data. Journal of Engineering Geology 20(2): 145-151. (in Chinese)

Xu Q, Peng DL, Zhang S, Zhu X, He CY, Qi X, Zhao, KY, Xiu DH, Ju NP (2020) Successful implementations of a real-time and intelligent early warning system for loess landslides on the Heifangtai terrace, China, Engineering Geology 278.

Xu Q, Yuan Y, Zeng Y, Hack R (2011) Some new pre-warning criteria for creep slope failure. Science China Technological Sciences 54: 210-220.

Yin YP, Huang B, Chen X, Liu GN Wang SC (2015) Numerical analysis on wave generated by the Qianjiangping landslide in Three Gorges Reservoir, China. Landslides 12(2): 355-364.

Zhou DP, Zhu BZ, Mao JQ (1995) The Principle of Rheological Mechanics and Its Applications in Geotechnique. Chengdu: Southwest Jiaotong University Press. (in Chinese) 


\section{Figures}

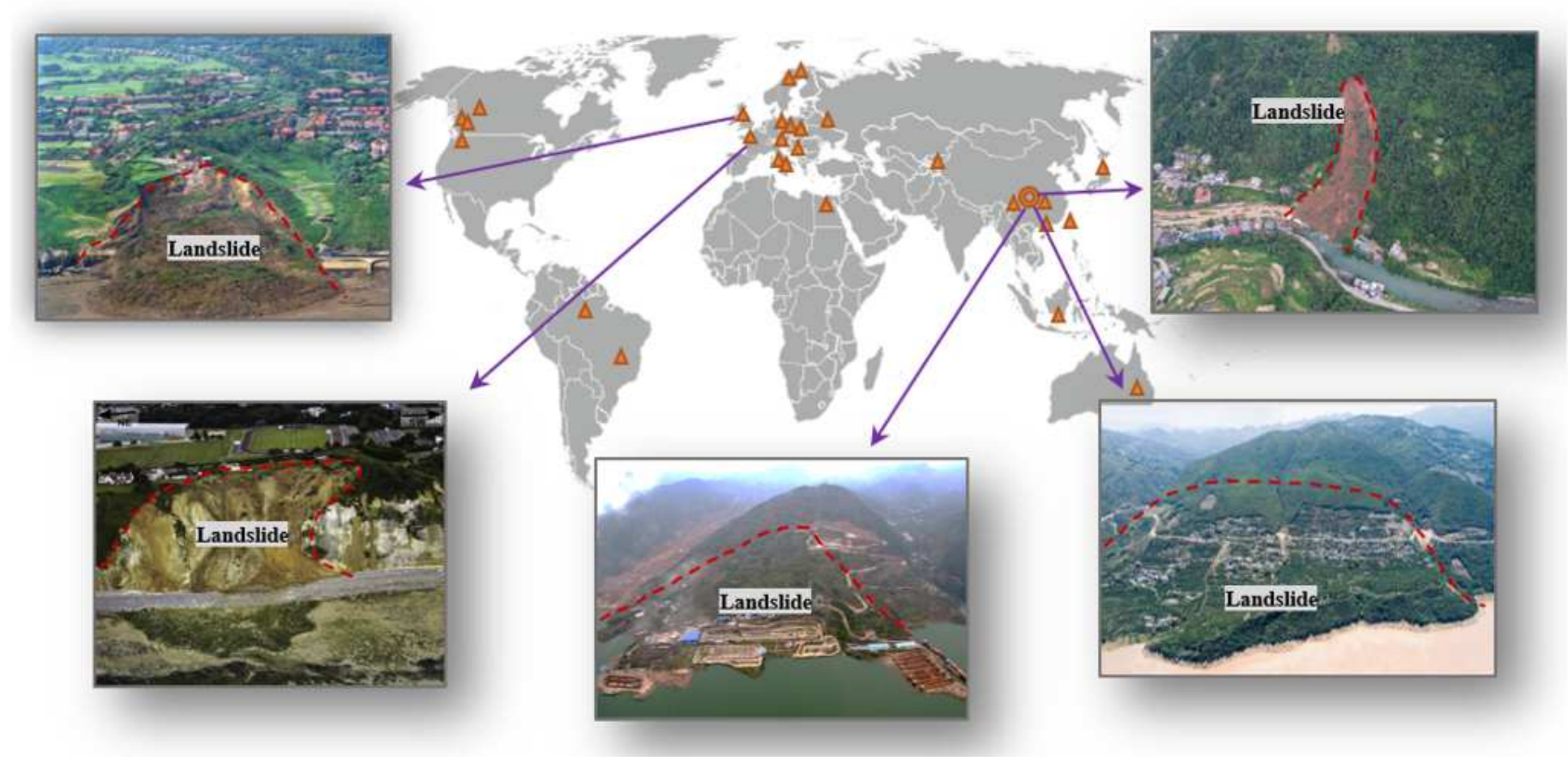

\section{Figure 1}

Part of regional landslide hazards in the world Note: The designations employed and the presentation of the material on this map do not imply the expression of any opinion whatsoever on the part of Research Square concerning the legal status of any country, territory, city or area or of its authorities, or concerning the delimitation of its frontiers or boundaries. This map has been provided by the authors.

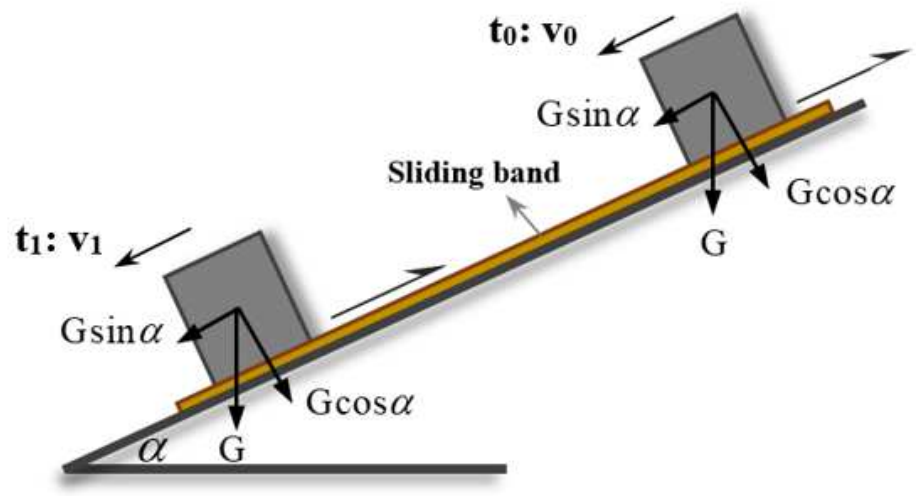
(a) $\tau_{\infty}<\tau \stackrel{\text { Gradually }}{\longrightarrow} \tau_{\infty} \ll \tau \longrightarrow$ Later instability
(b) $\tau_{\infty} \ll \tau \stackrel{\text { Rapidly }}{\longrightarrow}$ Later instability
(c) $\tau_{\infty}<\tau \stackrel{\text { Gradually }}{\longrightarrow} \tau<\tau_{\infty} \longrightarrow$ Stable creep

Figure 2

Simplified landslide mechanics modes(a) progressive deformation mode;(b) sudden deformation mode; (c) steady deformation mode 


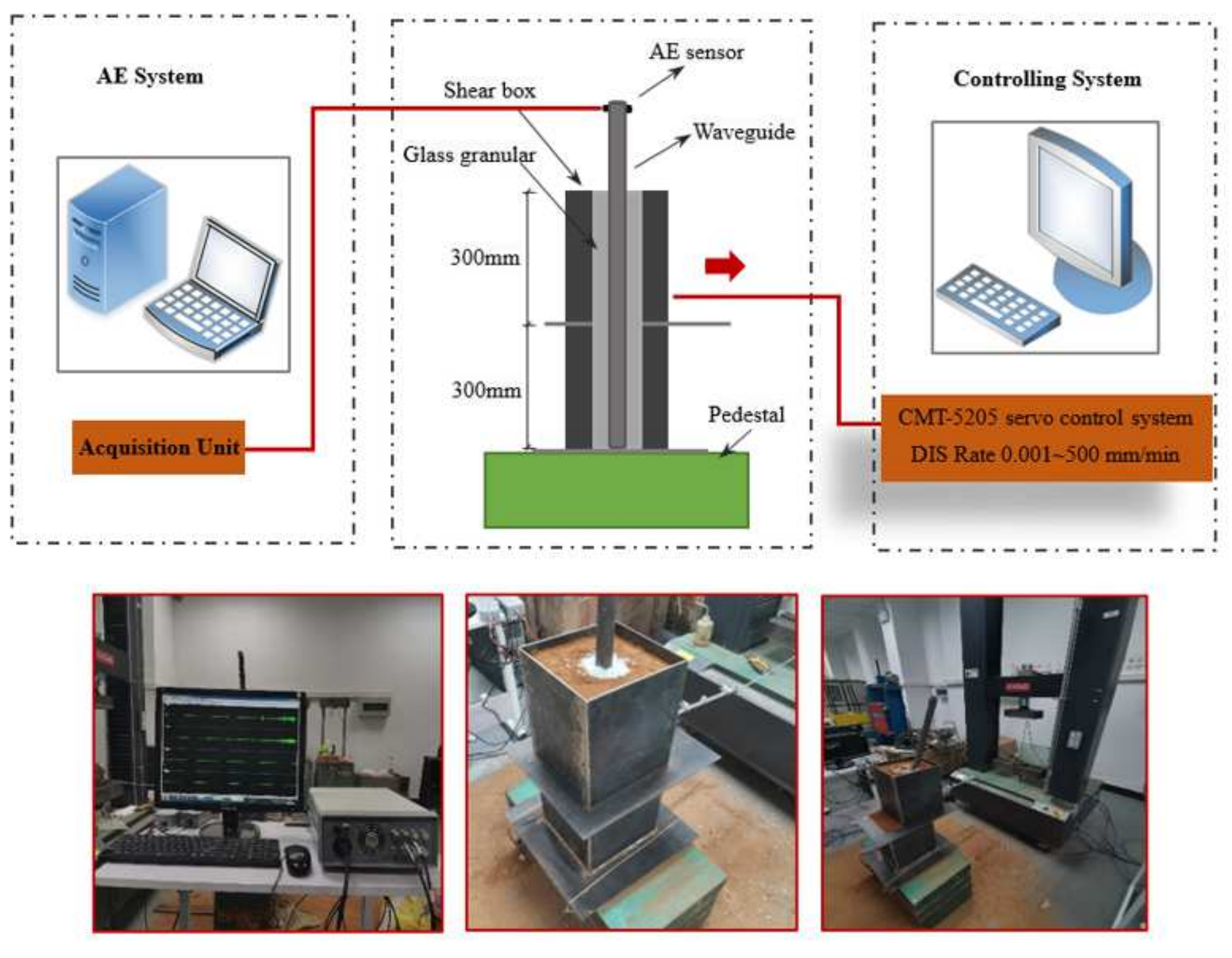

Figure 3

Experimental apparatus 


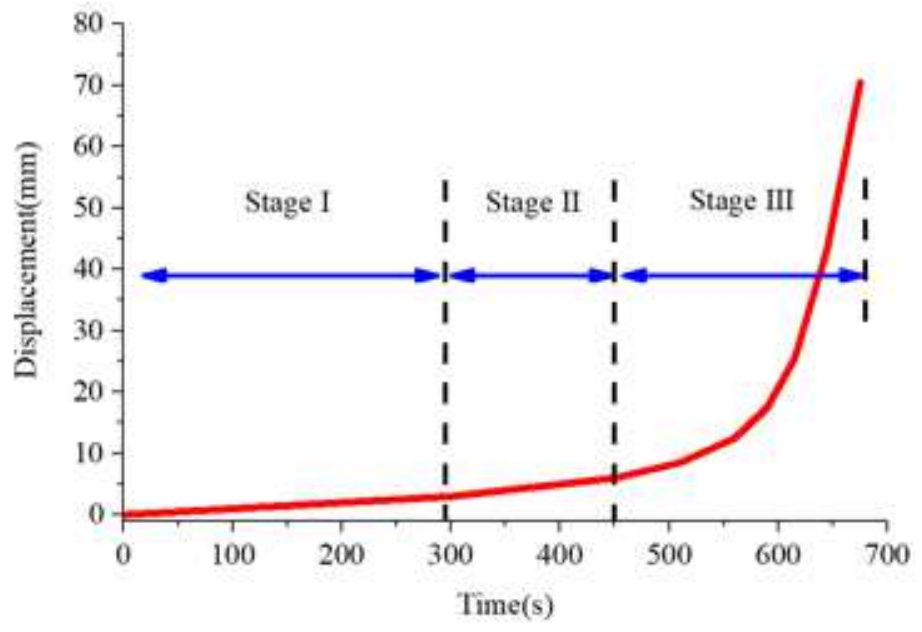

(a)

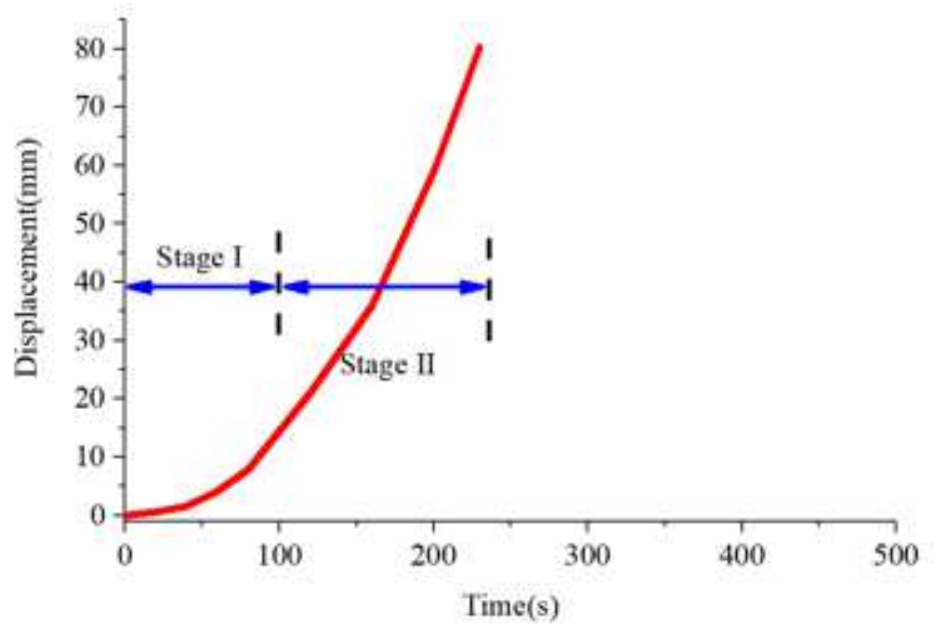

(b)

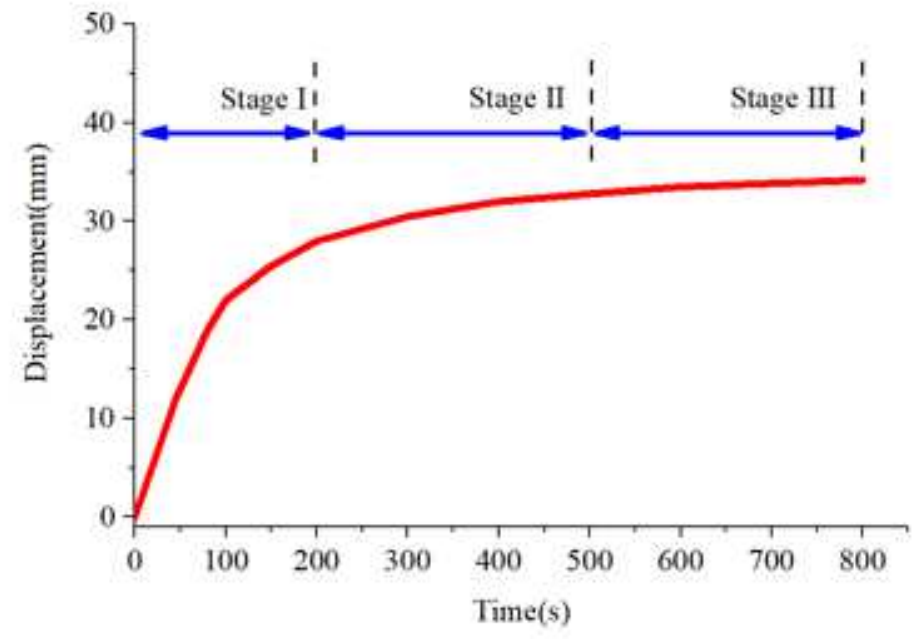

(c)

\section{Figure 4}

Displacement-time curve(a) progressive deformation mode;(b) sudden deformation mode;(c) steady deformation mode 


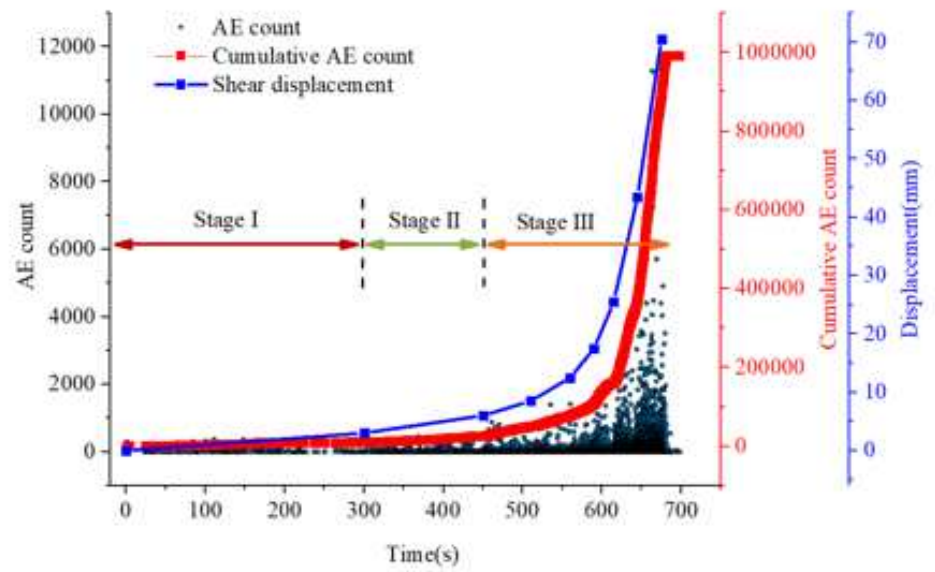

(a)

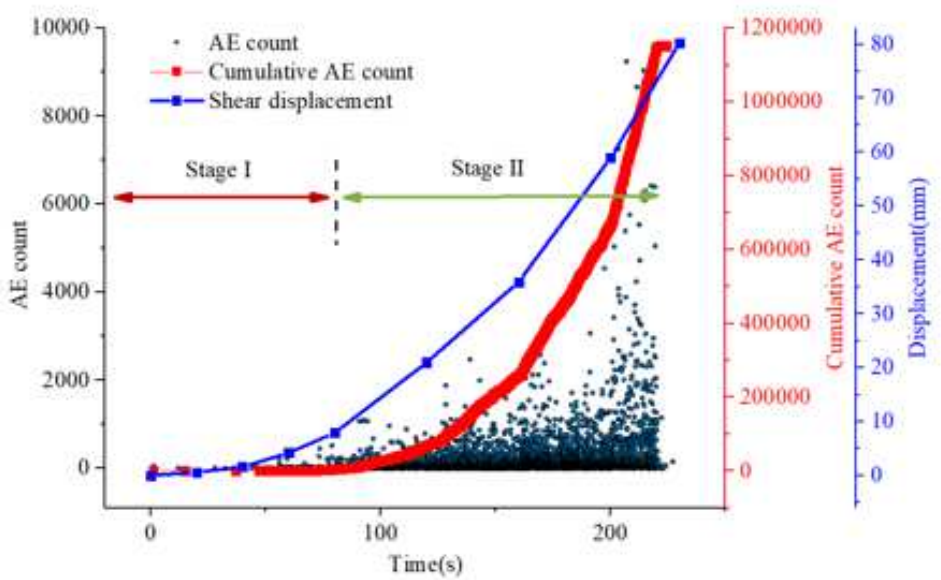

(b)

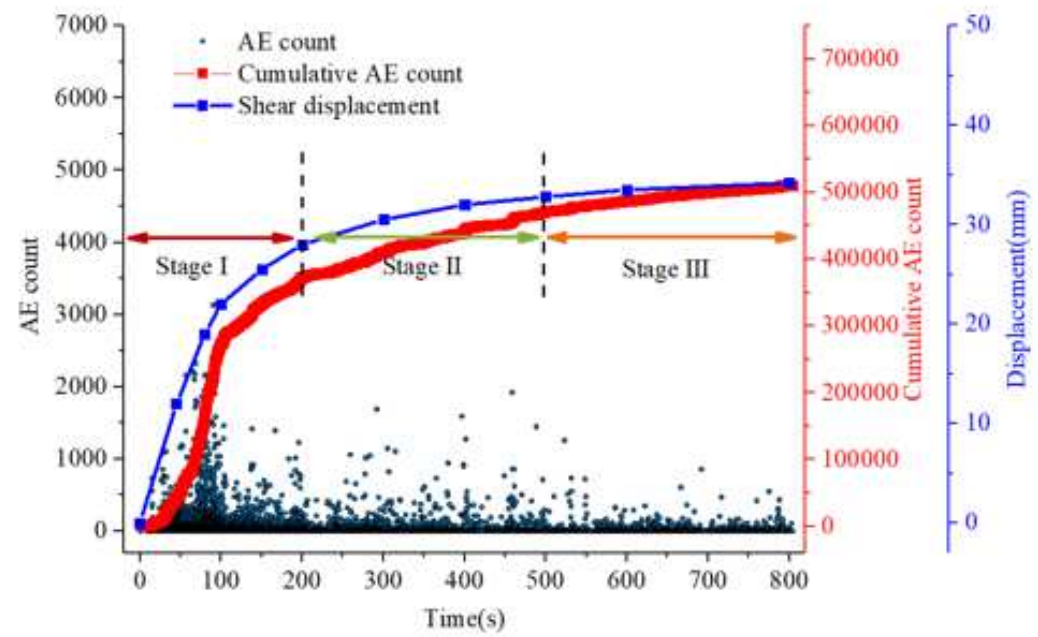

Figure 5

The AE count, cumulative AE count and shear surface displacement for east test (a) progressive deformation mode;(b) sudden deformation mode;(c) steady deformation mode 




(a)



(b)



(c)

\section{Figure 6}

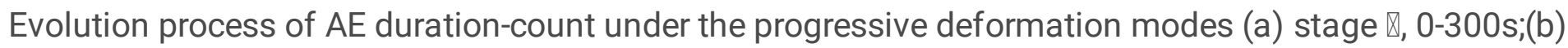






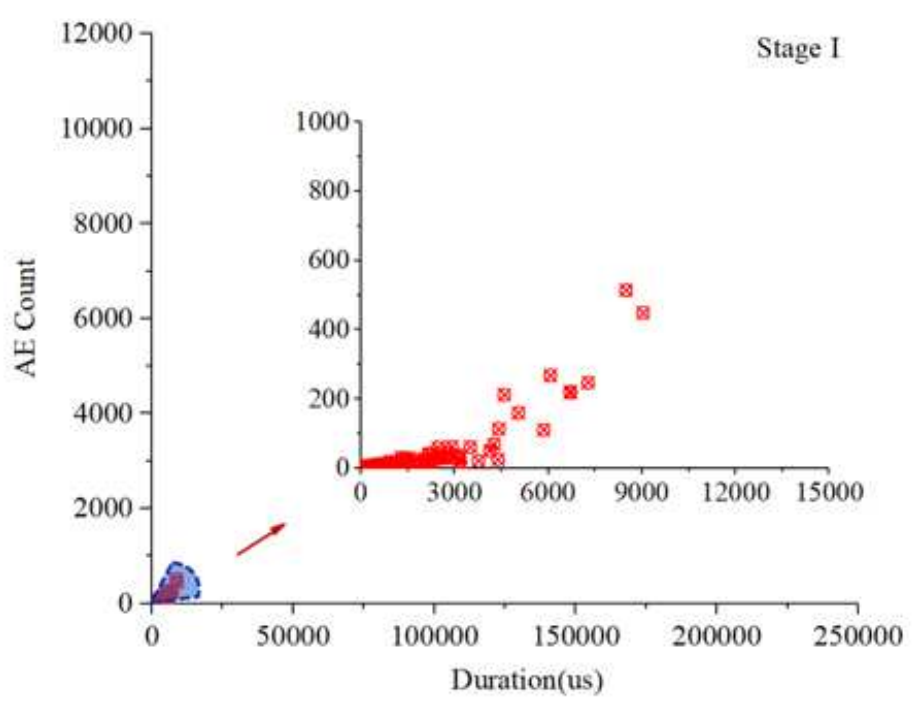

(a)

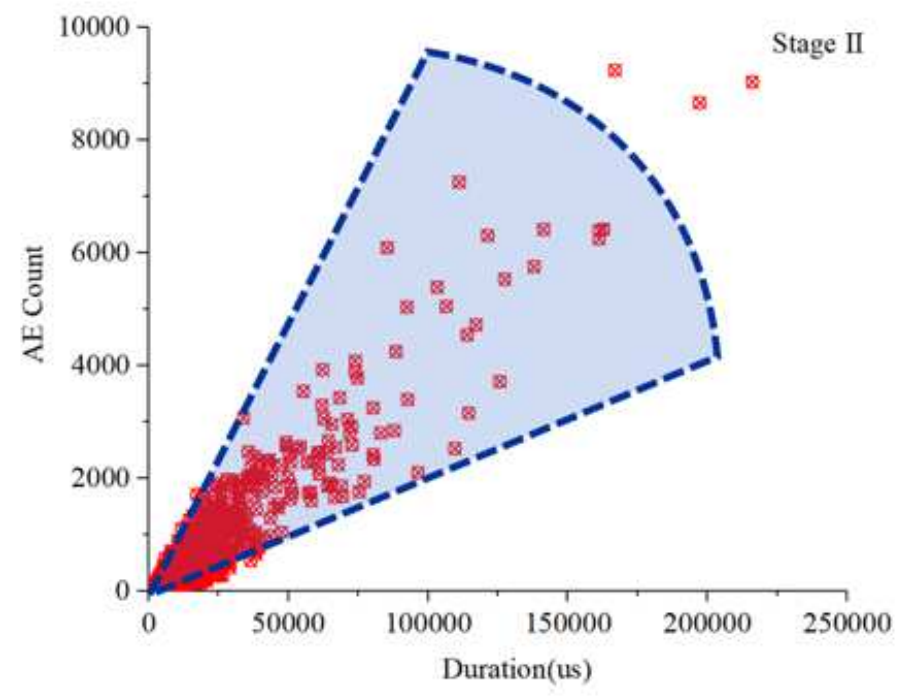

(b)

\section{Figure 7}

Evolution process of $A E$ duration-count under the sudden deformation mode (a) stage $\varangle, 0-80$ s; (b) stage $\nabla$, 80-230s 


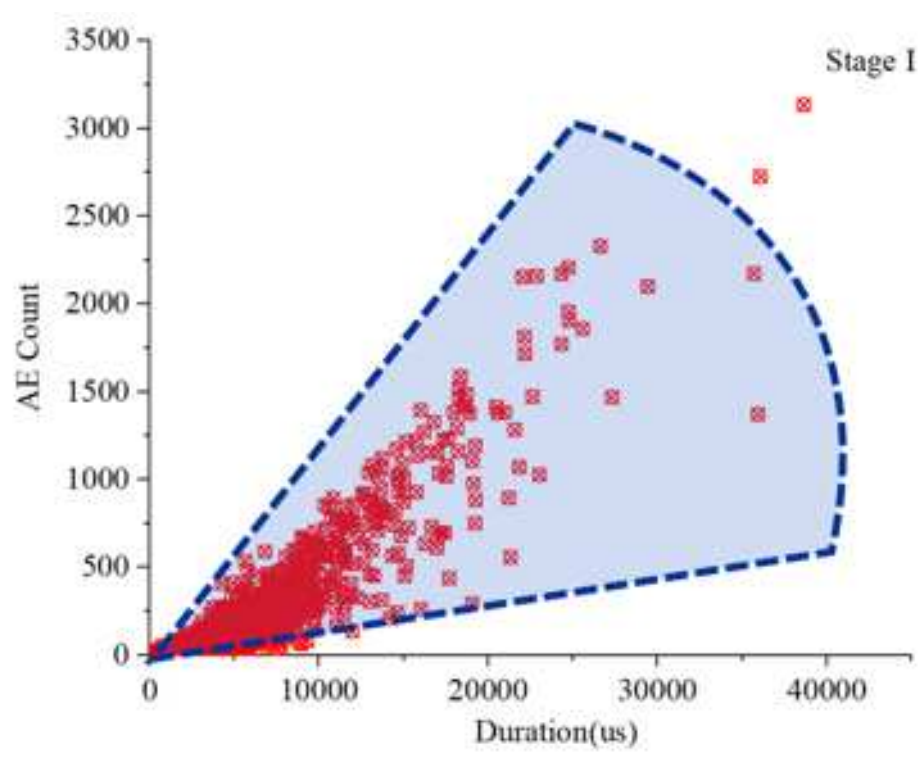

(a)

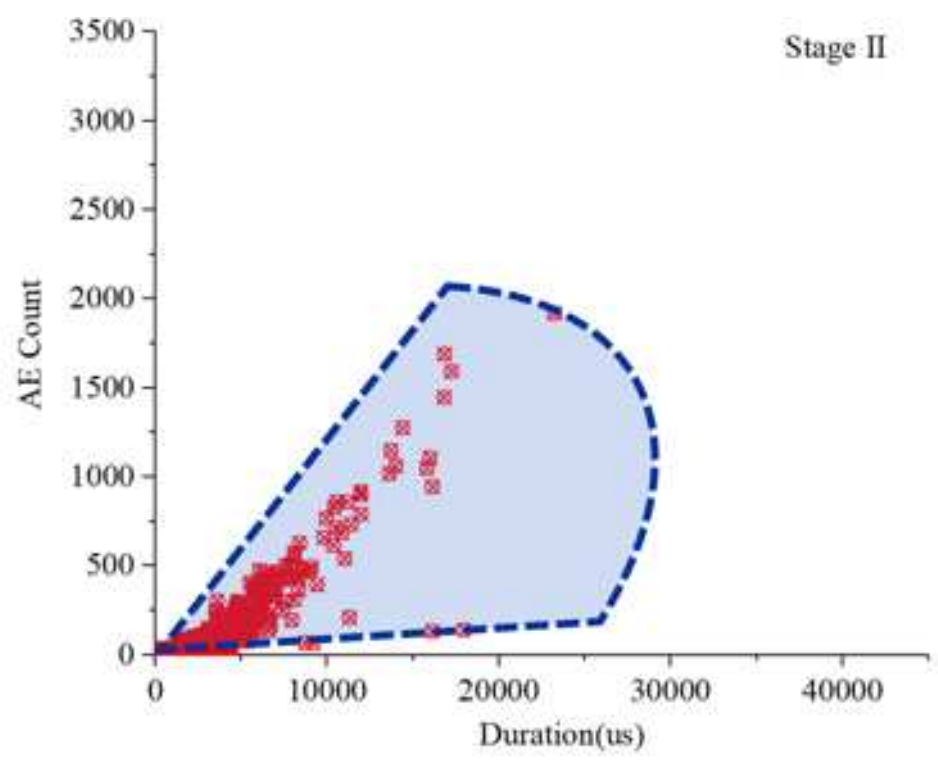

(b)

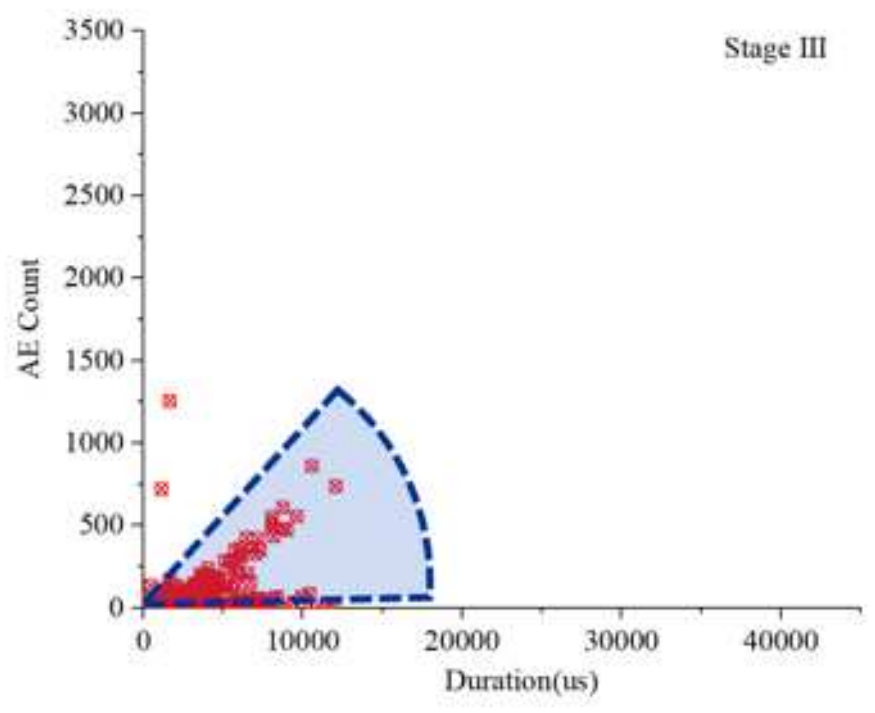

(c)

Figure 8

Evolution process of $A E$ duration-count under the steady deformation mode (a) stage $\varangle, 0-200 \mathrm{~s} ;(\mathrm{b})$ stage $\nabla$ 200-500s;(c) stage $\mathbb{X}, 500-800$ s 


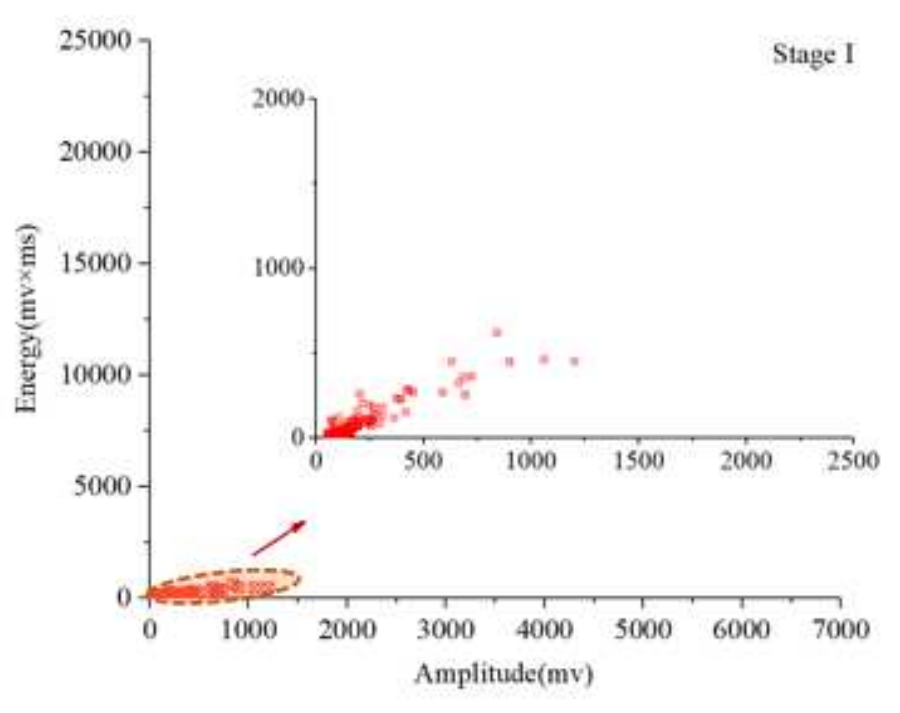

(a)

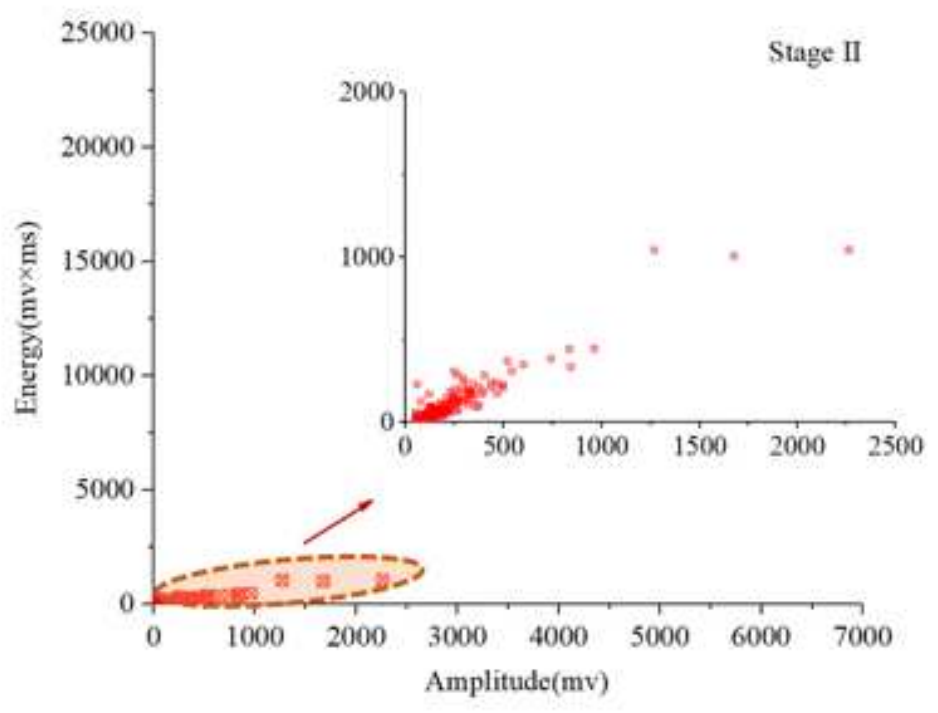

(b)

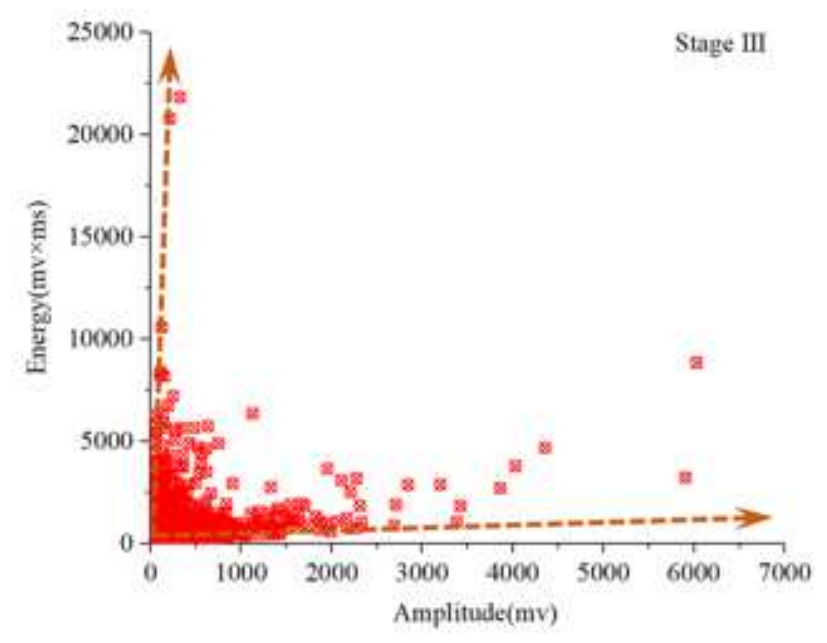

(c)

\section{Figure 9}

Evolution process of $A E$ amplitude-energy under the progressive deformation mode (a) stage $\Downarrow, 0-300 \mathrm{~s}$;

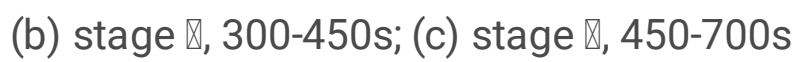




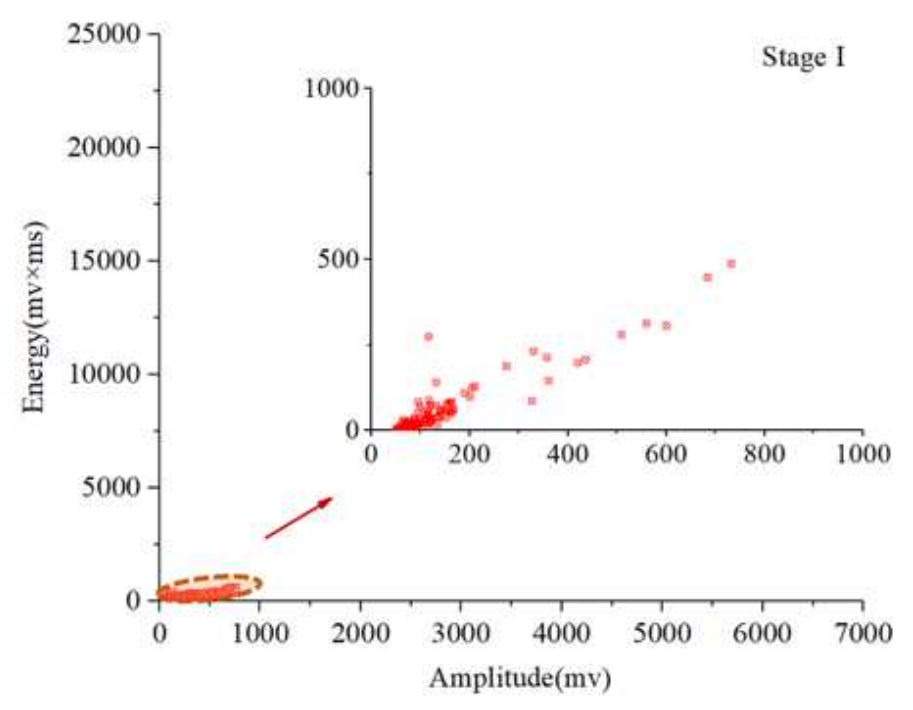

(a)

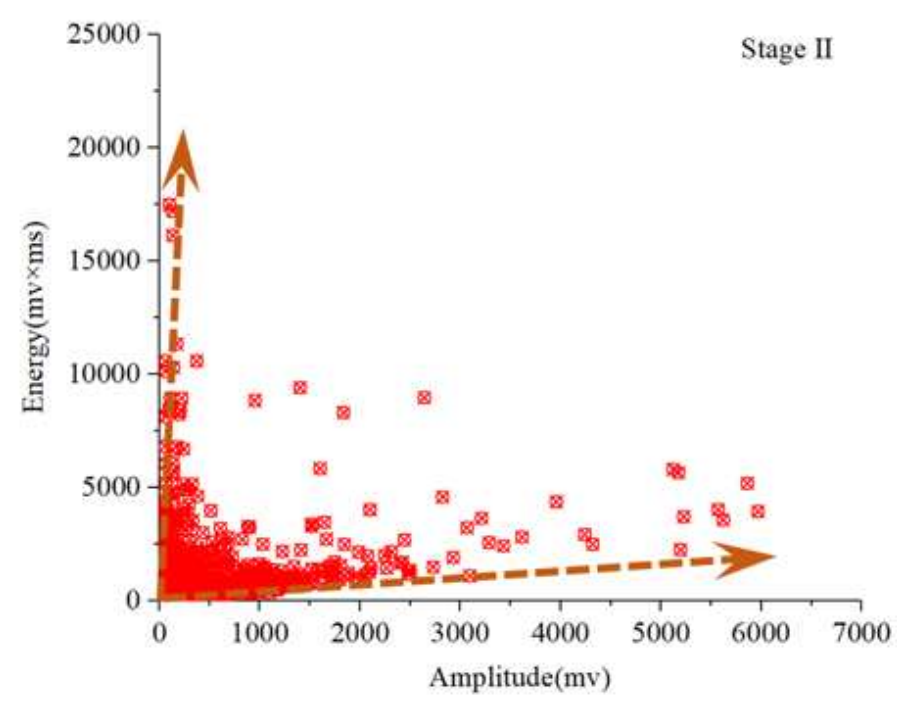

(b)

\section{Figure 10}

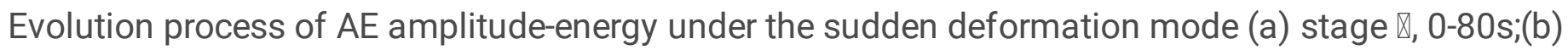

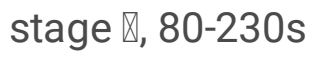




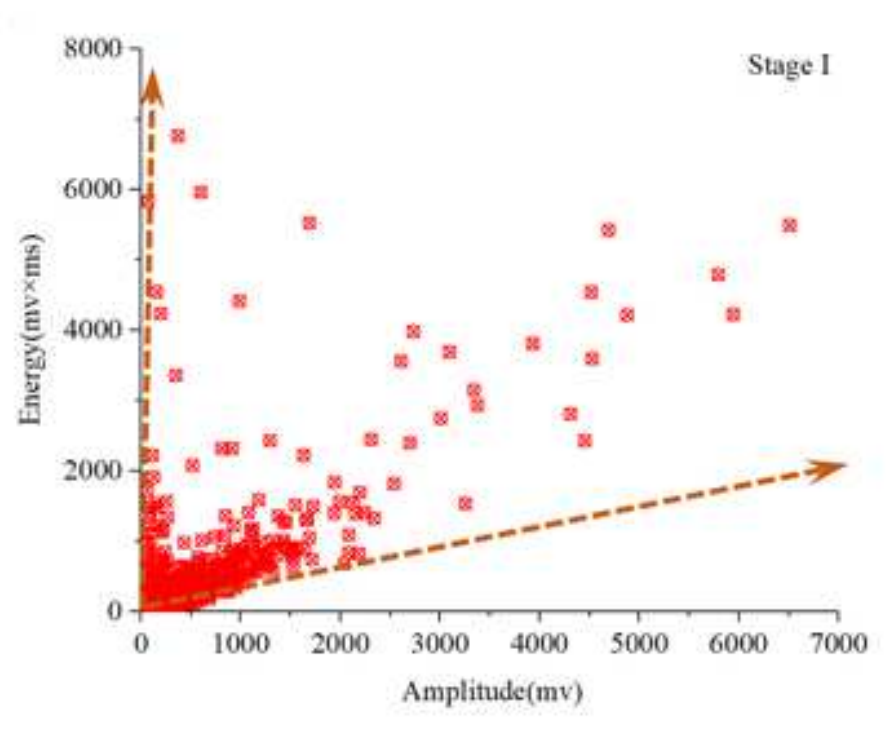

(a)



(b)

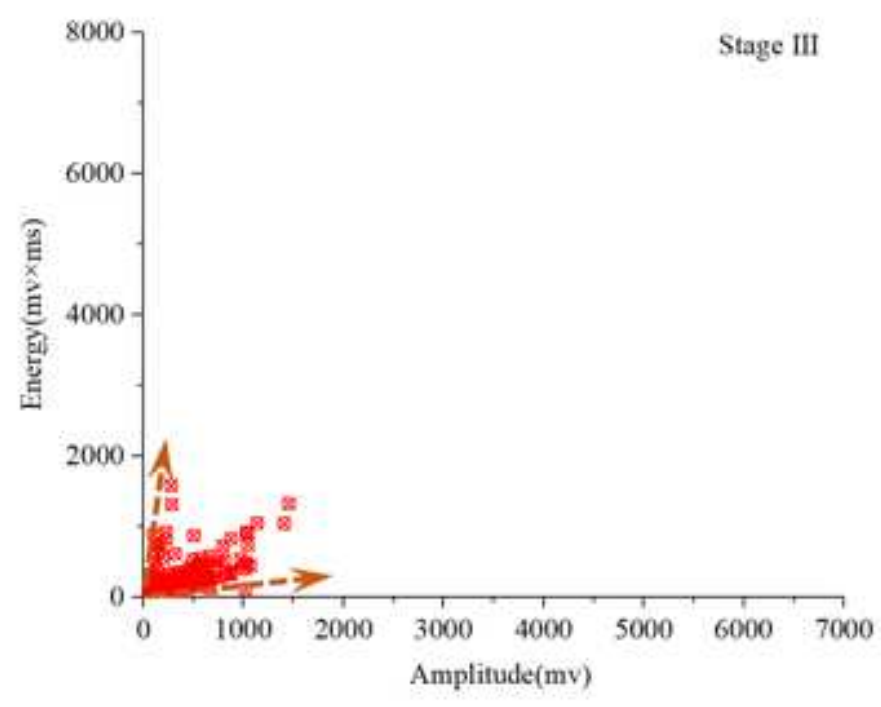

(c)

\section{Figure 11}

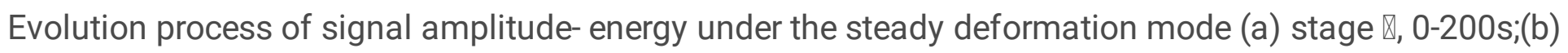
stage $\otimes 200-500$ s; (c) stage $\otimes, 500-800$ s 


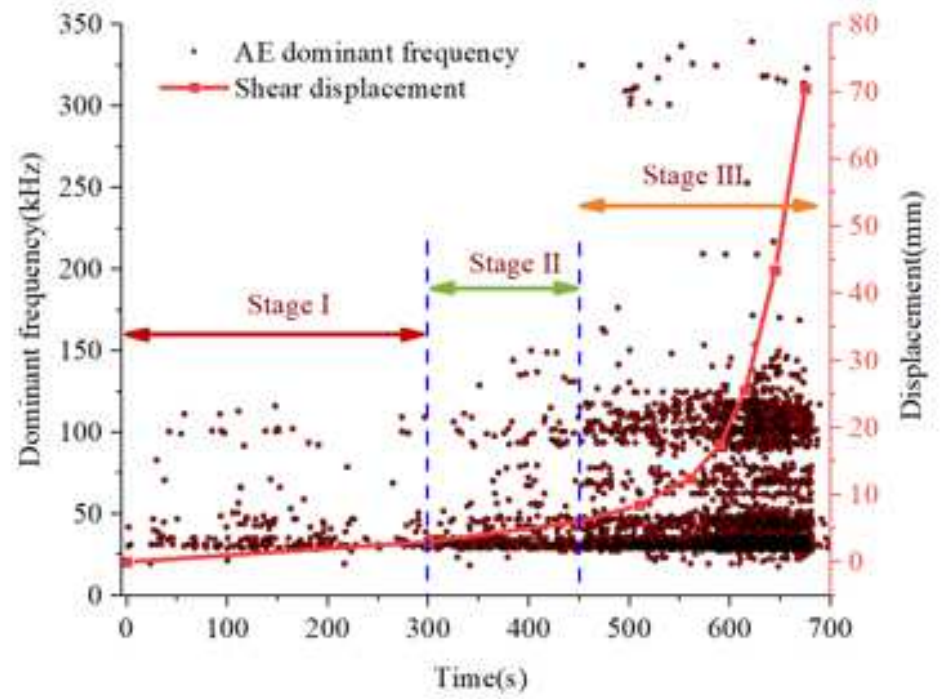

(a)



(b)

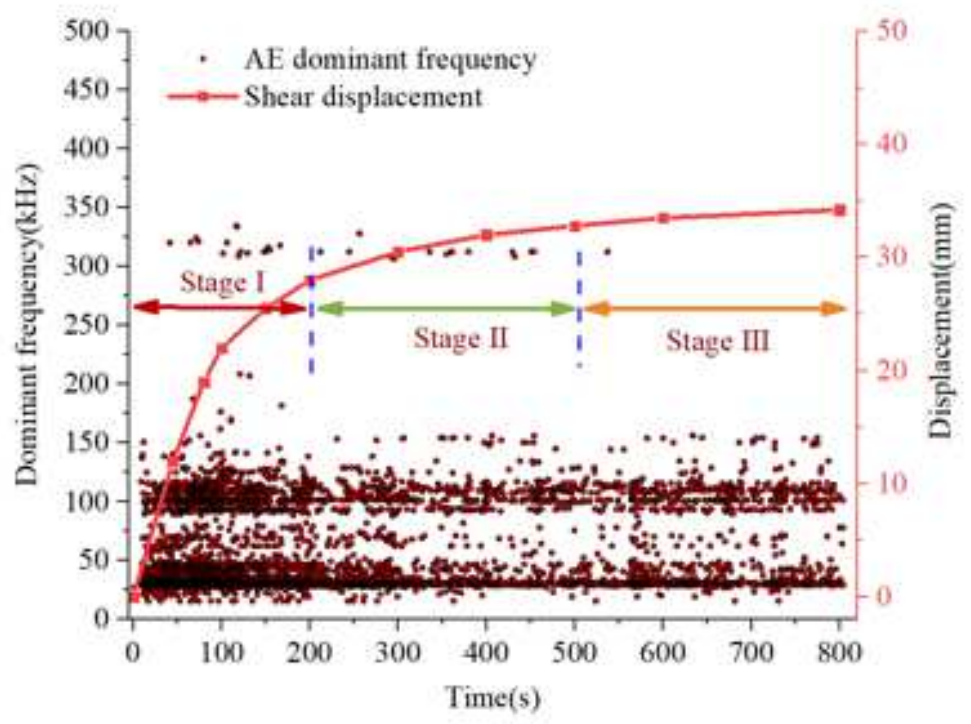

(c)

\section{Figure 12}

The AE dominant frequency evolution and shear displacement in the entire test process(a) progressive deformation mode;(b) sudden deformation mode;(c) steady deformation mode 


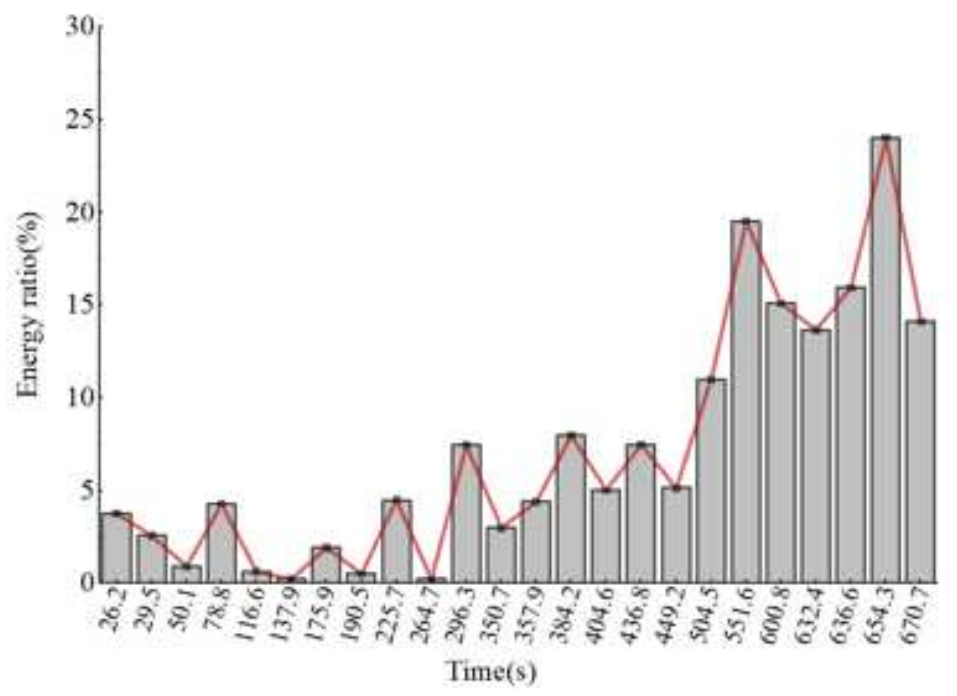

(a)

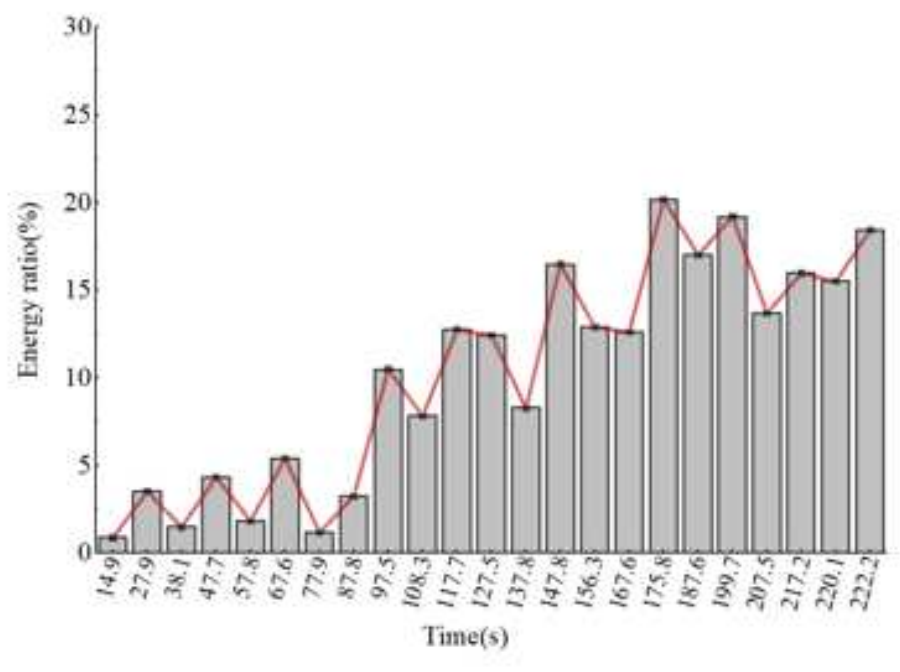

(b)

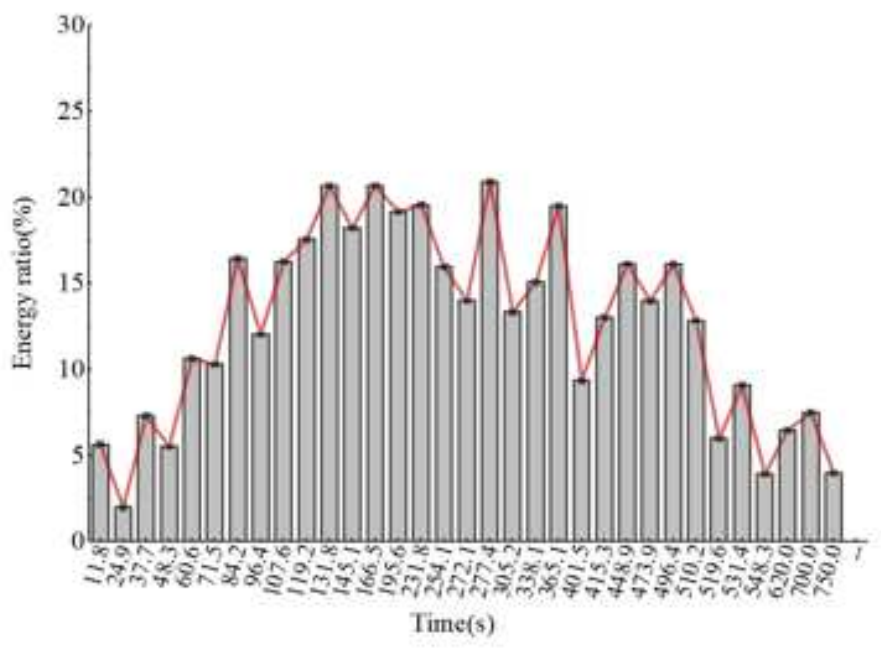

(c)

\section{Figure 13}

Energy ratio of the high frequency band against time(a) progressive deformation mode;(b) sudden deformation mode;(c) steady deformation mode

Figure 14

Evolution characteristics of $\mathrm{AE}$ amplitude in different deformation modes(a) progressive deformation mode;(b) sudden deformation mode;(c) steady deformation mode
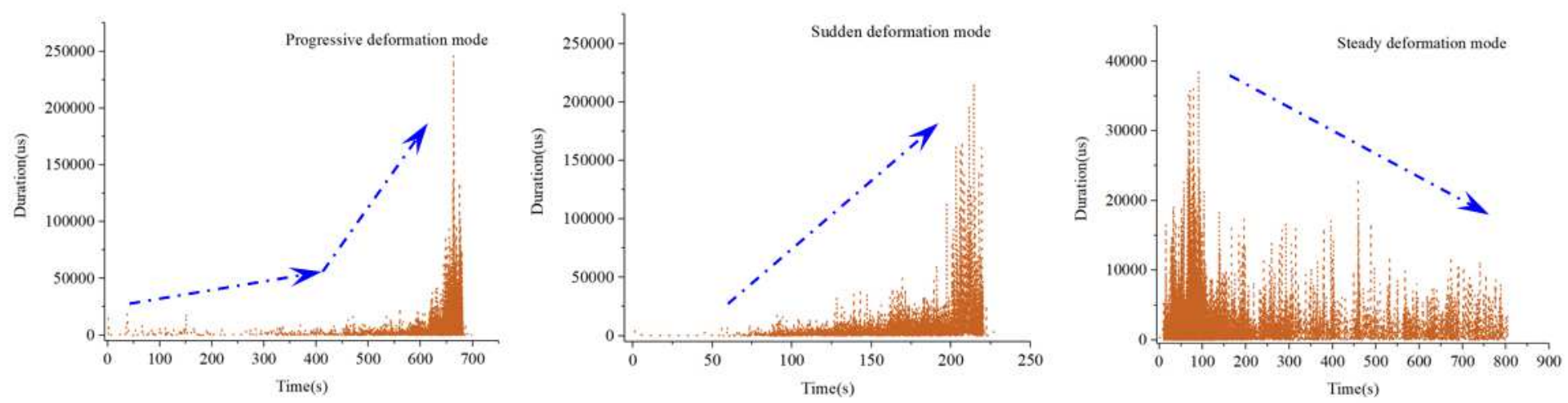

\section{Figure 15}

Evolution characteristics of AE duration in different deformation modes(a) progressive deformation mode;(b) sudden deformation mode;(c) steady deformation mode
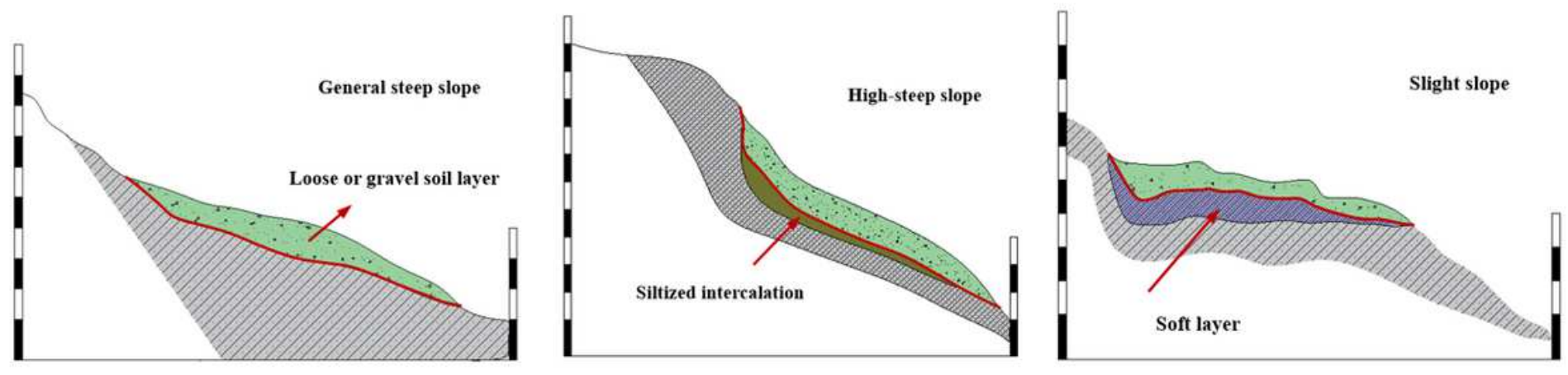

Figure 16

Generalized geological model for probable landslide modes(a) progressive landslide mode;(b) sudden landslide mode;(c) steady landslide mode 